Document downloaded from:

http://hdl.handle.net/10251/117819

This paper must be cited as:

Pereiro-Barceló, J.; Bonet Senach, JL.; Albiol Ibáñez, JR. (2018). Required tie spacing to prevent inelastic local buckling of longitudinal reinforcements in RC and FRC elements. Engineering Structures. 160:328-341. https://doi.org/10.1016/j.engstruct.2018.01.048

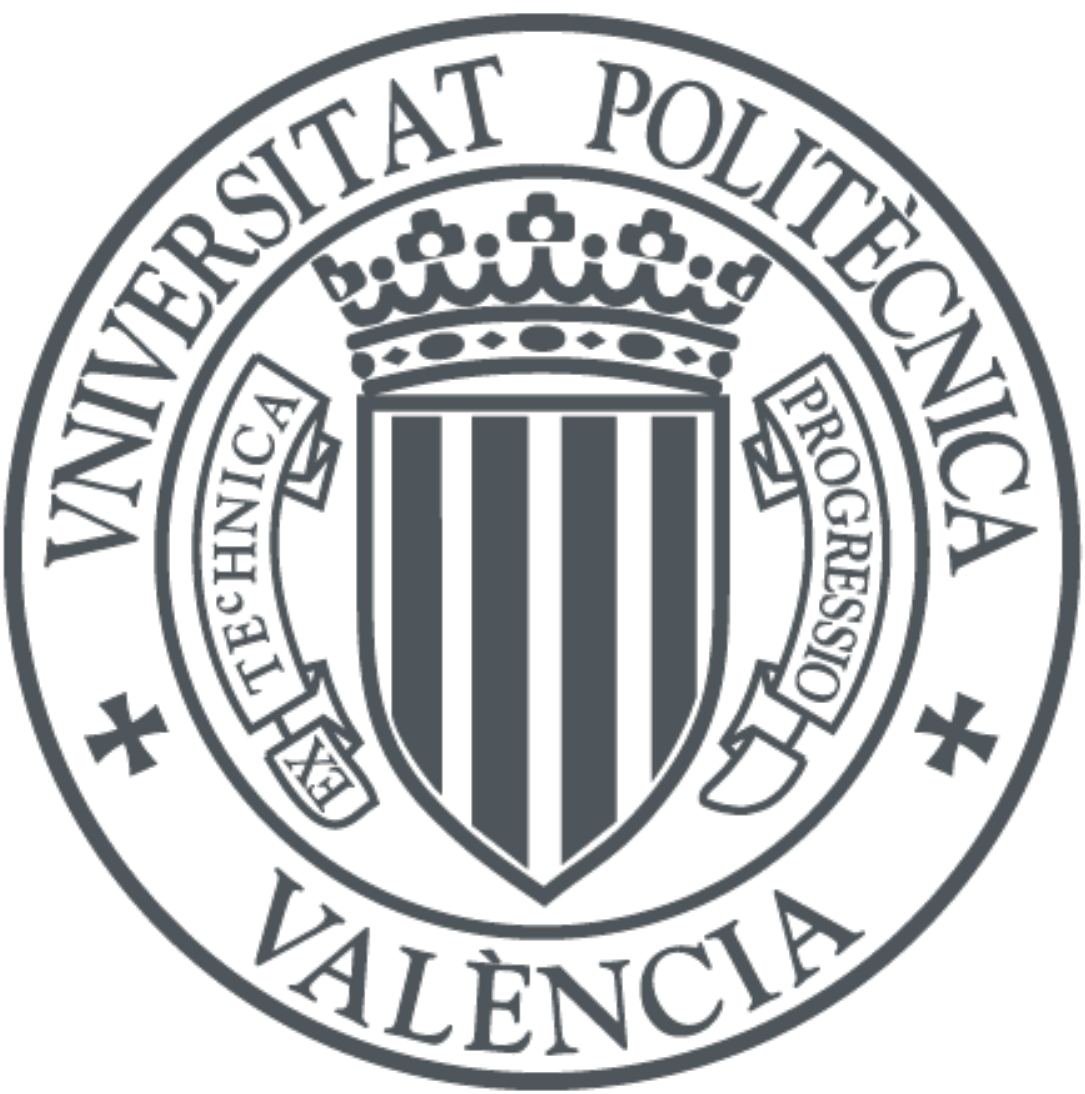

The final publication is available at

https://doi.org/10.1016/j.engstruct.2018.01.048

Copyright Elsevier

Additional Information 


\title{
Required tie spacing to prevent inelastic local buckling of longitudinal reinforcements in RC and FRC elements
}

\author{
Javier Pereiro-Barcelóa, José L. Bonet Senach ${ }^{\mathrm{a}, *}$, José R. Albiol-Ibáñez ${ }^{\mathrm{b}}$ \\ ${ }^{a}$ Construction Engineering and Civil Engineering Projects Department, ICITECH, Universitat Politècnica de València, C/Vera unnumbered, Valencia 46022, Spain \\ ${ }^{\mathrm{b}}$ DCAR (Architectonic Constructions Department), Universitat Politècnica de València, C/Vera unnumbered, Valencia 46022, Spain
}

\section{A R T I C L E IN F O}

\section{Keywords:}

Buckling reinforcement

High strength concrete

Fiber-reinforced concrete

RC columns

\begin{abstract}
A B S T R A C T
Compressed reinforcement buckling in concrete columns can reduce ductility in structural elements. In order to avoid this, design codes propose maximum required tie spacing. Nonetheless, they do not incorporate the positive effect of concrete fibers in their formulation, whose capability of delaying buckling has been proved. For this reason, recommendations for maximum required tie spacing for elements made with concrete, with or without steel fibers, and with normal or high strength, are proposed in this article. In order to achieve this, the mixed model proposed by Pereiro-Barceló and Bonet was extended to consider elements made of HSC with and without steel fibers thanks to the results of an experimental campaign of HSC columns with and without fibers, under monotonic loading. In these tests, the buckling critical load in compressed reinforcement was experimentally determined in all the columns. In addition, a comparison of the proposed transverse concrete separation with respect to the recommendations proposed by the main existing codes was made.
\end{abstract}

\section{Introduction}

Compressed reinforcement buckling can reduce both strength and deformation capacity in reinforced concrete (RC) elements in buildings and bridges [1]. One of the functions of transverse reinforcement is to provide enough stiffness to prevent compressed longitudinal reinforcement from buckling. Inadequate transverse reinforcement arrangement can cause longitudinal reinforcement to buckle under high compressive strains when the concrete cover spalls, or with fiber-reinforced concrete, when concrete fibers are inefficient [2].

According to the elastic theory, Bresler and Gilbert [3] propose a relation between reinforcement separation $s$ and the diameter of longitudinal reinforcement $D$. They make buckling stress equal the yield stress of longitudinal reinforcement. According to these authors, in order to develop maximum longitudinal reinforcement effectiveness, the tie spacing must allow buckling stress that equals the yield stress of longitudinal reinforcement to be achieved, even when the concrete cover has spalled. These authors also propose a relation between the diameter of the longitudinal and transverse reinforcement by assuming that the deflected shape of the buckled bar affects up to two tie intervals. Also according to the elastic theory, Scribner [4] assume that buckling affects up to three tie intervals. Neither research work takes into account that buckling behavior is strongly influenced by the shape of the stress-strain curve within the reinforcing bar inelastic range (both longitudinal and transverse bars). For this reason, Papia et al. [5] employ the reduced modulus theory to analyze the inelastic buckling of longitudinal reinforcement. Pereiro-Barceló and Bonet [2] extend the Papia et al. [5] model by considering the fiber-reinforced concrete cover and its degradation. Mau and El-Mabsout [6] analyze behavior in isolated bars through finite elements simulation and determine that for $s / D$ to be superior to 16 , post-buckling load capacity must be smaller than the yield load. Based on the same numerical simulation, Mau [7] observe that if $s / D$ is lower than a critical value, the yield plateau has a negligible effect. Mau [7] also reports that critical relation $s / D$ is located between 5 and 7 for the steel he used. For greater separations, steel bars can become unstable after longitudinal reinforcement yields.

Pantazopoulou [8] proposes a method to calculate buckling loads that depend on stirrup separation. This method is based on the forces equilibrium of the buckled bar. This author assumes the deformed shape of the buckled bar to be cosenoidal in shape. Pantazopoulou [8] points out that the tangent modulus of longitudinal reinforcement depends on whether yield stress has been achieved or not. If yield stress is not achieved, the elasticity modulus is used, otherwise the reduced

\footnotetext{
* Corresponding author.

Email addresses: japebar@upv.es (J. Pereiro-Barceló); jlbonet@cst.upv.es (J.L. Bonet Senach); joalib1@csa.upv.es (J.R. Albiol-Ibáñez)
} 
modulus is used. Pantazopoulou [8] proposes a procedure based on expanding the concrete core to know the strain that stirrups undergo and, consequently, if they are yielded or not.

Dhakal and Maekawa [9] use an energy equilibrium method to calculate critical buckling load, which allows them to know transverse reinforcement separation. The stiffness of transverse reinforcements is considered by means of elasto-plastic springs (null axial stiffness after achieving yield stress). These authors eliminate the stirrups closer to half the buckling length because they tend to enter the plastic zone rather than those that are far away. After conducting a parametric study about the number of stirrups to be eliminated, they propose minimum stiffness for transverse reinforcement, which is related to transverse reinforcement separation. Kashani et al. [10] proves that Dhakal and Maekawa [9] buckling model is in good agreement with the experimental results. Dhakal [11] extends the proposed method by Dhakal and Maekawa [9] to consider the fiber-reinforced concrete cover. This method bears in mind the concrete cover discretely at the stirrup location, but does not consider the cover degradation that results from overestimating buckling stress. Other authors [12-15] use buckled bar energy equilibrium methods to obtain critical load expressions depending on stirrup separation. Both transverse reinforcements [12,13,15] and concrete cover [14] are considered distributedly along instability length. With these methods, tie spacing can be obtained to not allow, for example, the bar to buckle before yield stress is achieved.

Several authors propose constitutive curve of steel bars including buckling [16-18], even considering corroded steel bars [19,20], and finite element models to obtain the constitutive curves including buckling [21].

As Pereiro-Barceló and Bonet [2] point out, the aforementioned analytical models followed to estimate the critical buckling load of compressed bars are not valid for the whole range of transverse reinforcement separations and do not consider progressive fiber concrete cover degradation. Only the mixed model proposed by Pereiro-Barceló and Bonet [2] is valid for any tie spacing because it contemplates transverse reinforcement discretely and the fiber concrete cover distributedly, and it also considers fiber concrete cover degradation.

Design codes propose separations for transverse reinforcement to prevent compressed reinforcements from buckling [22-25]. Nevertheless, these recommendations do not take into account the favorable effect of steel fibers in concrete [2,26,27].

Consequently, this article proposes design recommendations to determine the required tie spacing in elements made of normal strength concrete (NSC), fiber-reinforced normal strength concrete (FRNSC), high strength concrete (HSC) and fiber-reinforced high strength concrete (FRHSC). To achieve this, the model of Pereiro-Barceló and Bonet [2] was used. This model was calibrated for NSC and FRNSC elements. In order to extend the model application field, an experimental campaign of HSC and FRHSC columns was performed.

\section{Determining critical buckling stress}

This section briefly describes simplified expressions to determine the critical buckling stress proposed by Pereiro-Barceló and Bonet [2]. These expressions are used in Section 4 to propose the recommendations of the required separation of transverse reinforcements for NSC, FRNSC, HSC and FRHSC elements.

\subsection{Critical buckling stress}

The mixed model of Pereiro-Barceló and Bonet [2] provides the buckling critical stress of passive reinforcements in NSC and FRNSC elements. It contemplates stirrups discretely and the concrete cover con- tinuously. The model is based on two fundamental parameters: the stiffness of transverse reinforcement $\alpha_{s}$ and the distributed stiffness of concrete cover $\alpha_{c}$. The expression of $\alpha_{s}$ is shown in Expression (1):

$\alpha_{s}=\frac{E_{s w} \cdot A_{s w}}{L_{e f}}$

where:

$E_{s w}$ : the tangent modulus of transverse reinforcement. In order to know this modulus, it is necessary to determine if reinforcement is yielded or not. For this purpose, it is necessary to relate the transverse strain to the longitudinal strain through the dilatancy parameter [28-31].

$A_{s w}$ : the transverse reinforcement area.

$L_{e f}$ : the effective transverse reinforcement length, which depends on the reinforcement arrangement and the type of load (concentric or eccentric) [2].

The distributed stiffness of cover $\alpha_{c}$ was calibrated experimentally for NSC and FRNSC. The value of $\alpha_{c}=70 \mathrm{MPa}$ was experimentally obtained. This value can be guaranteed until a longitudinal reinforcement strain of $\varepsilon_{\text {crit, } \eta \text { ?1 }}$ (Expression (2)) is achieved, which depends on $f_{R, 1}$ (residual tensile strength that corresponds to a Crack Mouth Opening Displacement (CMOD) of $0.5 \mathrm{~mm}$ in the flexural tensile strength test (UNE EN 14651:2007 [32])). Beyond this strain, the fiber reinforced concrete cover is too degraded and a null value of $\alpha_{c}$ is considered ( $\alpha_{c}=0 \mathrm{MPa}$ ).

Once the $\alpha_{s}$ and $\alpha_{c}$ values are known, buckling critical stress $\sigma_{\text {crit }}$ can be obtained through the following expression:

$\sigma_{\text {crit }}=c_{c} \frac{\pi^{2} E_{r} I}{s^{2} A}$

where:

$s$ : Transverse reinforcement separation.

$E_{r}$ : The reduced modulus of the longitudinal reinforcement proposed by Papia et al. [5].

I: The inertia moment of longitudinal reinforcement.

$A$ : The transverse reinforcement area.

$c_{c}$ : The critical adimensional stress $c_{c}$ (4)-(7). $c_{c}$ is the relation between the critical buckling stress of the bar and the critical buckling stress of the bar hinged between two consecutive rigid stirrups $\left(\frac{\pi^{2} E_{r} I}{s^{2} A}\right)$.

$$
\begin{aligned}
& \text { If } k_{c s}=0 \\
& c_{c}=4 \cdot\left(1-\frac{1}{1+0.09 \gamma^{0.58}}\right)
\end{aligned}
$$

$$
\begin{aligned}
& \text { If } 0<k_{c s} \leqslant 30 \\
& c_{c}=a_{1} \cdot e^{b_{1} \cdot \log _{10} \gamma}+c_{1} \quad \text { when } \quad c_{c} \geqslant c_{c_{\eta=1.4}}(\gamma)
\end{aligned}
$$

where:

$$
\begin{aligned}
a_{1} & =0.35 k_{c s}^{0.5}-0.0066 \\
b_{1} & =\frac{1.15 k_{c s}+0.035}{k_{c s}+0.029} \\
c_{1} & =\frac{-0.0116 k_{c s}+0.062}{k_{c s}+0.036}
\end{aligned}
$$


$c_{c}=a_{2} \cdot e^{b_{2} \cdot \log _{10} \gamma}+c_{2}$ when $c_{c}<c_{c_{\eta=1.4}}(\gamma)$

where:

$a_{2}=\frac{5.5 k_{c s}^{3}+99.3 k_{c s}^{2}+189 k_{c s}+91.2}{k_{c s}^{3}+93 k_{c s}^{2}+417 k_{c s}+25.4}$

$b_{2}=\frac{1.14 k_{c s}^{2}+1.26 k_{c s}+0.08}{k_{c s}^{2}+1.535 k_{c s}+0.404}$

$c_{2}=\frac{-0.02 k_{c s}^{2}-0.375 k_{c s}-1.07}{k_{c s}^{2}+5 k_{c s}+0.325}$

If $k_{c s}>30$

$c_{c}=\left(\frac{s}{\pi}\right)^{2} \sqrt{\frac{12 \alpha_{c}}{E_{r} I}}$

where:

$\gamma=\alpha_{s} s^{3} / E_{r} I$

$k_{c s}=\frac{\alpha_{c}}{\alpha_{s}} s$

$c_{c_{\eta=1.4}}(\gamma)=-0.00124\left(\log _{10} \gamma\right)^{7}+4.8$

\subsection{Simplified calculation of reduced modulus $E_{r}$}

In order to simplify the reduced modulus $E_{r}$ calculation, expression (11) is proposed to apply the method of Papia et al. [5]. The proposed expression is valid only for steel bars and it depends only on the yield stress of the steel under compression $f_{y, c}$.

$E_{r}(\mathrm{MPa})=7 f_{y, c}(\mathrm{MPa})+400$
Expression (11) provides a lower bound of $E_{r}$. Consequently, the application of this expression to calculate critical stress $\sigma_{\text {crit }}$ and transverse reinforcement $s$ separation provides values on the security side. In order to deduce this expression, the following procedure was followed:

- It was assumed that the plastic modulus of steel $E_{h}$ was zero in tension.

- The method proposed by Dodd and Restrepo [33] was applied to obtain the modulus of the plastic branch in compression $E_{h, c}$ (Table 1). It was applied for the different yield stresses of the steel in compression $f_{y, c}(200-1000 \mathrm{MPa})$ and for different elasticity moduli $E_{s}$ (180-220 GPa).

- The method proposed by Papia et al. [5] was applied to calculate reduced modulus $E_{r}$ (Table 1 ). The elasticity modulus of $180 \mathrm{GPa}$ provides the lowest reduced modulus $E_{r}$. Fig. 1 shows the relation $E_{r}-f_{y, c}$ for a modulus $E_{s}$ that equals $180 \mathrm{GPa}$.

- A linear regression was performed of the obtained results, $E_{s}$ equals $180 \mathrm{GPa}$. The regression parameters were simplified. The result of the adjustment is observed in Fig. 1. Determination coefficient $R^{2}$ is 0.9991 .

\section{Experimental program}

The final goal of the experimental program was to extend the model of Pereiro-Barceló and Bonet [2], which is summarized in Section 2, to propose recommendations for the maximum required tie spacing for NSC and HSC concrete, both with and without fibers (Section 4).

\subsection{Specimens}

Nine eccentrically loaded dog bone-shaped RC columns were tested (Fig. 2). The height of columns was $1350 \mathrm{~mm}$. The end had a $400 \times 200 \mathrm{~mm}$ section to apply eccentricity to the load. The central part had a squared section of a $200-\mathrm{mm}$ side (Fig. 3) and was $700 \mathrm{~mm}$ long. Each specimen had a geometric cover of $20 \mathrm{~mm}$. The diameter of the longitudinal reinforcements was $12 \mathrm{~mm}$ on the compressed side and $16 \mathrm{~mm}$ on the tensioned one (Fig. 3). The aim of this asymmetry was to accomplish high strains in compressed longitudinal reinforcements.

Stirrup separation $s$ was 5,10 and $30 \mathrm{~cm}$ and, therefore, three $s / D$ ratios were considered: $4.16,8.33$ and 25 , where $\mathrm{D}$ is the diameter of the longitudinal reinforcement. The $s / D=4.16$ ratio was lower than the maximum ratio proposed by EN 1998-1:2004 [23] for high ductility columns (DHC) or by ACI318R-14 [25] for special frames, which is $s / D=6$ in both codes. The $s / D=8.33$ ratio approximately equals the

Table 1

Reduced modulus approach for null $E_{h}$ in tension.

\begin{tabular}{|c|c|c|c|c|c|c|c|}
\hline \multirow[t]{2}{*}{$f_{y, c}(\mathrm{MPa})$} & \multicolumn{2}{|l|}{$E_{s}=180 \mathrm{GPa}$} & \multicolumn{2}{|c|}{$E_{s}=200 \mathrm{GPa}$} & \multicolumn{2}{|c|}{$E_{s}=220 \mathrm{GPa}$} & \multirow[t]{2}{*}{$E_{r}(11)$} \\
\hline & $E_{h, c}$ & $E_{r}$ (Papia et al. [5]) & $E_{h, c}$ & $E_{r}$ (Papia et al. [5]) & $E_{h, c}$ & $E_{r}$ (Papia et al. [5]) & \\
\hline 200 & 406.70 & 1708.90 & 406.63 & 1720.70 & 406.57 & 1731.10 & 1800.00 \\
\hline 300 & 610.55 & 2489.50 & 610.40 & 2509.60 & 610.27 & 2527.20 & 2500.00 \\
\hline 400 & 814.74 & 3242.20 & 814.47 & 3271.20 & 814.25 & 3296.70 & 3200.00 \\
\hline 450 & 916.97 & 3609.90 & 916.63 & 3643.60 & 916.35 & 3673.30 & 3550.00 \\
\hline 500 & 1019.28 & 3972.60 & 1018.85 & 4011.00 & 1018.51 & 4044.90 & 3900.00 \\
\hline 550 & 1121.67 & 4330.50 & 1121.16 & 4373.90 & 1120.74 & 4412.10 & 4250.00 \\
\hline 600 & 1224.15 & 4684.10 & 1223.54 & 4732.50 & 1223.04 & 4775.20 & 4600.00 \\
\hline 650 & 1326.71 & 5033.70 & 1325.99 & 5087.20 & 1325.41 & 5134.40 & 4950.00 \\
\hline 700 & 1429.36 & 5379.40 & 1428.53 & 5438.10 & 1427.85 & 5489.90 & 5300.00 \\
\hline 800 & 1634.91 & 6060.40 & 1633.82 & 6129.70 & 1632.93 & 6190.80 & 6000.00 \\
\hline 900 & 1840.79 & 6728.50 & 1839.42 & 6808.60 & 1838.30 & 6879.40 & 6700.00 \\
\hline 1000 & 2047.02 & 7385.00 & 2045.33 & 7476.10 & 2043.94 & 7556.70 & 7400.00 \\
\hline
\end{tabular}




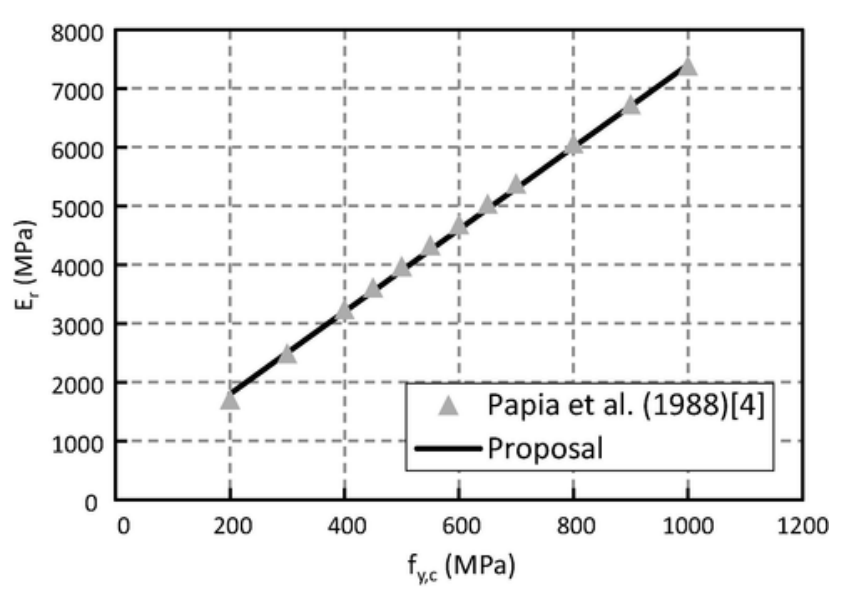

Fig. 1. Approximation of $E_{r}$ by considering $E_{h}=0$ and $E_{s}=180 \mathrm{GPa}$.

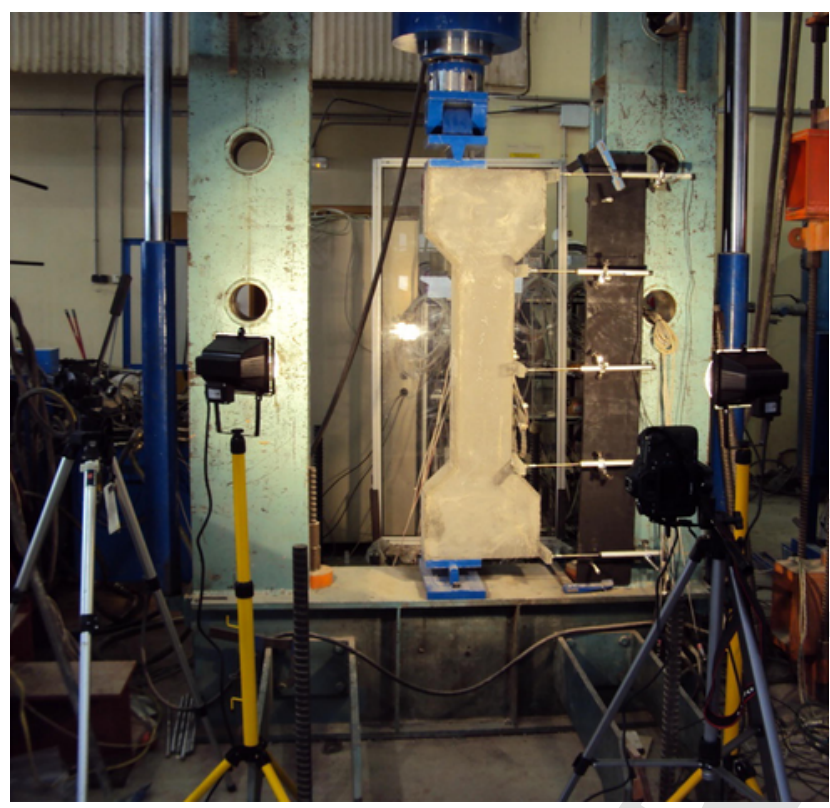

Fig. 2. Outer configuration of tests.

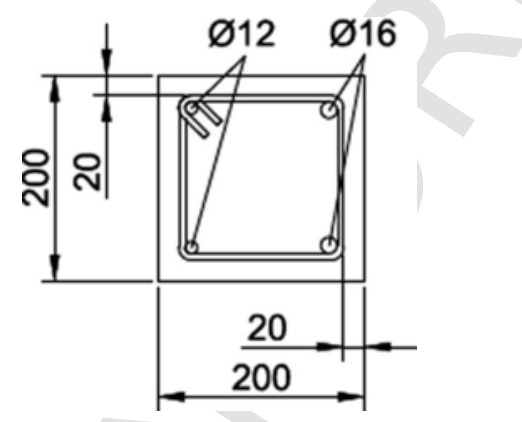

Fig. 3. Central section (units in $\mathrm{mm}$ ).

ratio proposed by EN 1988-1:2004 [23] for medium ductility (DCM) columns or by ACI-318R-14 [25] for ordinary frames, which is $s / D=8$ in both codes. Finally, the $\mathrm{s} / \mathrm{D}=25$ ratio was higher than the ratio of EN 1992-1:2004 [34], whose maximum value is $s / D=20$. The objective in the last case was to analyze the delay in reinforcements buckling thanks to the steel fibers in FRHSC elements.

Table 2 presents the details of the nine supports included in the experimental program. Designation of specimens was FxSy, where " $x$ " in- dicates fiber content $\left(0,40\right.$ and $\left.80 \mathrm{~kg} / \mathrm{m}^{3}\right)$ and "y" indicates tie spacing $(5,10$ and $30 \mathrm{~cm})$. All the specimens were tested 28 days after being produced.

\subsection{Material characterization}

HSC is a self-compacting concrete of nominal compressive strength ( $80 \mathrm{MPa}$ ), with a steel fiber content of 0,40 and $80 \mathrm{~kg} / \mathrm{m}^{3}$. The aim of making self-compacting concrete is to facilitate the cast into the formwork because of the low water/cement ratio, especially when fiber content is $80 \mathrm{~kg} / \mathrm{m}^{3}$. HSC composition is: $525 \mathrm{~kg} / \mathrm{m}^{3}$ of Portland cement type I $52.5 \mathrm{R} ; 196 \mathrm{~kg} / \mathrm{m}^{3}$ of water; $450 \mathrm{~kg} / \mathrm{m}^{3}$ of gravel with a maximum $6 \mathrm{~mm}$ size; $1045 \mathrm{~kg} / \mathrm{m}^{3}$ of sand; $200 \mathrm{~kg} / \mathrm{m}^{3}$ of limestone filler; a superplasticizer quantity, which varies between 8.13 and $8.93 \mathrm{~kg} / \mathrm{m}^{3}$ depending on the amount of fibers of each concrete. Steel fibers are DRAMIX 80/30 BP, which have hook ends, are $30 \mathrm{~mm}$ long, and have a slenderness of 80 , a tensile strength of $3070 \mathrm{MPa}$ and an elasticity modulus of $200 \mathrm{GPa}$.

The concrete compressive strength of each support was obtained as the average of three cylindrical control specimens, which measured $150 \times 300 \mathrm{~mm}$ (UNE-EN 12390-3 [35]). For the mechanical characterization of the flexural strength of FRHSC, prismatic control specimens of $550 \times 150 \times 500 \mathrm{~mm}$ were made, according to UNE EN 14651:2007 [32]. The concrete characterization results are shown in Table 2, where: $f_{c m}$ is the average strength of concrete under compression (UNE-EN 12390-3 [35]), $E_{c}$ is the concrete elasticity modulus, $\varepsilon_{c 85}$ is the strain that corresponds to a stress $0.85 f_{\mathrm{cm}}$ denoted after peak load (measured on the softening branch), $f_{L O P}$ is the limit of proportionality in the flexural tensile strength test, $f_{R, 1}, f_{R, 2}, f_{R, 3}$ and $f_{R, 4}$ are the residual tensile strengths that correspond to the Crack Mouth Opening (CMOD) of 0.5, 1.5, 2.5 and $3.5 \mathrm{~mm}$, respectively (UNE EN 14651:2007 [32]).

Two different steel batches were used. Steel was B500SD C class (EN1992-1-1:2004 [34]). The results of the characterization tests of longitudinal or transverse reinforcements (UNE EN-10002-1 [36]) are shown in Table 3 , where $f_{y}, \varepsilon_{y}, f_{s h}, \varepsilon_{s h}, f_{u}, \varepsilon_{u}, E_{s}$, are respectively the yield stress, the strain that corresponds to the yield stress, the stress at which the hardening branch begins, the strain associated with $f_{\text {sh }}$, the maximum stress, the strain associated with the maximum stress and the elasticity modulus. If specimens were fabricated with batch 1 , the diameter of the stirrups was $6 \mathrm{~mm}$, and $8 \mathrm{~mm}$ if they were fabricated with batch 2 . Table 3 offers the mechanical characteristics of compressed bars, which were obtained from the mechanical characteristics in tension according to the procedure by Dodd and Restrepo-Posada [33].

\subsection{Test setup}

The boundary conditions of specimens were hinges on the ends, achieved by screwing two plaques into the ends of columns. Each plaque had a groove. The free length between hinges was $1.39 \mathrm{~m}$. Load was applied through knife edges seated in these grooves, with an eccentricity of $0.10 \mathrm{~m}$ on both sides. A $2500 \mathrm{kN}$ hydraulic actuator was employed. The tests were run by applying displacement control on the midspan section at a speed of $0.2 \pm 0.05 \mathrm{~mm} / \mathrm{min}$.

\subsection{Instrumentation}

Strain gauges were placed in each column in both the longitudinal and transverse reinforcements. Gauges were placed on the compressed and tensioned reinforcements, and were arranged equidistantly among stirrups. The gauges of compressed reinforcements were arranged in parallel to the compressed side of the element to detect buckling [2] so those gauges were placed in the concave side of the bar considering the 
Table 2

Concrete characterization.

\begin{tabular}{|c|c|c|c|c|c|c|c|c|c|c|c|}
\hline Specimen & $\begin{array}{l}s \\
(\mathrm{~cm})\end{array}$ & $\begin{array}{l}\text { Tie } \\
\text { diameter } \\
(\mathrm{mm})\end{array}$ & $\begin{array}{l}\text { Steel } \\
\text { batch }\end{array}$ & $\begin{array}{l}\mathrm{f}_{\mathrm{cm}} \\
(\mathrm{MPa})\end{array}$ & $\begin{array}{l}\mathrm{E}_{\mathrm{c}} \\
(\mathrm{MPa})\end{array}$ & $\begin{array}{l}\varepsilon_{\mathrm{c} 85} \\
(\% \circ)\end{array}$ & $\begin{array}{l}\mathrm{f}_{\mathrm{LOP}} \\
(\mathrm{MPa})\end{array}$ & $\begin{array}{l}\mathrm{f}_{\mathrm{R}, 1} \\
(\mathrm{MPa})\end{array}$ & $\begin{array}{l}\mathrm{f}_{\mathrm{R}, 2} \\
(\mathrm{MPa})\end{array}$ & $\begin{array}{l}\mathrm{f}_{\mathrm{R}, 3} \\
(\mathrm{MPa})\end{array}$ & $\begin{array}{l}\mathrm{f}_{\mathrm{R}, 4} \\
(\mathrm{MPa})\end{array}$ \\
\hline F00S05 & 5 & 6 & 1 & 80.31 & 35,938 & 4.2 & - & - & - & - & - \\
\hline F00S10 & 10 & 6 & 1 & 71.79 & 36,189 & 3.74 & - & - & - & - & - \\
\hline F00S30 & 30 & 6 & 1 & 81.87 & 36,441 & 4.6 & - & - & - & 2 & - \\
\hline F40S05 & 5 & 8 & 2 & 85.52 & 37,657 & - & 5.46 & 8.01 & 9.43 & 9.00 & 6.80 \\
\hline F40S10 & 10 & 8 & 2 & 85.19 & 37,584 & - & 4.38 & 4.79 & 5.94 & 6.12 & 5.47 \\
\hline F40S30 & 30 & 8 & 2 & 83.05 & 34,058 & - & 5.64 & 11.48 & 13.66 & 12.42 & 10.31 \\
\hline F80S05 & 5 & 8 & 2 & 78.80 & 37,365 & - & 8.88 & 14.65 & 17.39 & 15.82 & 12.55 \\
\hline F80S10 & 10 & 8 & 2 & 75.22 & 37,473 & - & 8.35 & 16.30 & 17.93 & 17.22 & 15.42 \\
\hline F80S30 & 30 & 6 & 1 & 80.22 & 35,474 & - & 6.58 & 13.64 & 13.77 & 8.57 & 5.75 \\
\hline
\end{tabular}

Table 3

Reinforcements characterization.

\begin{tabular}{|c|c|c|c|c|c|c|}
\hline \multirow[t]{3}{*}{ Batch } & & \multicolumn{3}{|c|}{ Longitudinal } & \multicolumn{2}{|c|}{ Transverse } \\
\hline & & \multicolumn{2}{|l|}{$\varnothing 12$} & \multirow[t]{2}{*}{$\varnothing 16$} & \multirow[t]{2}{*}{$\varnothing 6$} & \multirow[t]{2}{*}{$\varnothing 8$} \\
\hline & & Tension & Compression & & & \\
\hline \multirow[t]{7}{*}{1} & $\mathrm{f}_{\mathrm{y}}(\mathrm{MPa})$ & 545.37 & 546.90 & 560.55 & 494.1 & 550.26 \\
\hline & $\varepsilon_{\mathrm{y}}$ & 0.00266 & 0.00265 & 0.0029 & 0.0024 & 0.0026 \\
\hline & $\mathrm{f}_{\mathrm{sh}}(\mathrm{MPa})$ & 545.88 & 570.72 & 568.79 & 532.66 & 552.06 \\
\hline & $\varepsilon_{\mathrm{sh}}$ & 0.0225 & 0.0220 & 0.0212 & 0.016 & 0.036 \\
\hline & $\mathrm{f}_{\mathrm{u}}(\mathrm{MPa})$ & 638.12 & 790.43 & 657.02 & 654.22 & 633.31 \\
\hline & $\varepsilon_{\mathrm{u}}$ & 0.1129 & 0.1015 & 0.129 & 0.137 & 0.144 \\
\hline & $\mathrm{E}_{\mathrm{s}}(\mathrm{MPa})$ & 205,027 & 206,112 & 193,781 & 205,875 & 211,640 \\
\hline \multirow[t]{7}{*}{2} & $\mathrm{f}_{\mathrm{y}}(\mathrm{MPa})$ & 574.40 & 577.74 & 550 & - & 554.76 \\
\hline & $\varepsilon_{\mathrm{y}}$ & 0.0029 & 0.0029 & 0.0027 & - & 0.0028 \\
\hline & $\mathrm{f}_{\mathrm{sh}}(\mathrm{MPa})$ & 577.10 & 596.88 & 552.7 & - & 555.85 \\
\hline & $\varepsilon_{\mathrm{sh}}$ & 0.0170 & 0.0167 & 0.017 & - & 0.0162 \\
\hline & $\mathrm{f}_{\mathrm{u}}(\mathrm{MPa})$ & 686.41 & 842.22 & 652.51 & - & 645.23 \\
\hline & $\varepsilon_{\mathrm{u}}$ & 0.1077 & 0.0972 & 0.1099 & - & 0.3229 \\
\hline & $\mathrm{E}_{\mathrm{s}}(\mathrm{MPa})$ & 197,993 & 199,721 & 205,678 & - & 195,329 \\
\hline
\end{tabular}

bar deformed shape before buckling. If buckling did not occur, strains would grow with the increasing applied load. Nevertheless, with gauges arranged as so, the recorded strain would diminish when reinforcement buckled, or tension would even be recorded. Therefore, onset of buckling is detected when compressed bar changes its curvature and, consequently, most compressed fibers of the cross section of the bar diminishes its compression strain level. A detailed description of this methodology to detect buckling of the compressed bar is depicted in Pereiro-Barceló and Bonet [2]. Gauges placed in transverse reinforcements ware arranged every two consecutive stirrups.

Moreover, a synchronized recording system was used (Fig. 2) in which each photogram was assigned with the corresponding applied load. The aim of this system was to correct the error due to the local effect of the bar curvature as a result of the special gauges arrangement. Correction was achieved from the tensioned bar strains and from the position of the neutral fiber, obtained by analyzing photographs.

Five linear voltage displacement transductors (LVDTs) were placed at $0,325,675,1025$ and $1350 \mathrm{~mm}$ from the lower specimen end to obtain the deformed shape of specimens at all times.

\subsection{Results and discussion}

Fig. 4 displays the normalized vertical load $\left(v=N /\left(A_{c} f_{c m}\right)\right)$ - longitudinal reinforcement strain $\left(\varepsilon_{l}\right)$ diagram, where $N$ is the load applied by the hydraulic actuator, $A_{c}$ is the gross area of the section and $f_{c m}$ is the average concrete strength under compression. The strain $\varepsilon_{l}$ was directly measured from strain gauges. The results were grouped according to fiber content. The normalized vertical load $(v)$ - normalized displacement $\left(\Delta / L_{\text {tot }}\right)$ diagram is on the right side, where $\Delta$ is the displacement in the midspan and $L_{t o t}$ is the distance among hinges. These diagrams point out the onset of buckling. Table 4 offers the experimental results in both the peak load situation and the local buckling situation of the compressed bar. The last two columns of Table 4 display the results of applying the analytical model explained in Sections 2.1 and 3.6.

Regarding the peak load situation, thanks to their tests with NSC or FRNSC, Pereiro-Barceló and Bonet [2] affirmed that the maximum load capacity of columns slightly increased when fiber content rose, and also when stirrup separation reduced due to greater confinement. With the HSC specimens, a slight increase in the peak load was observed when fiber content rose. However, an increase of the maximum load was not observed with reduced tie spacing. This happened because the effective confinement caused by transverse reinforcement reduced with higher concrete strength, and also because of the test inherent dispersion. One noteworthy aspect was that the load capacity of the F80S30 column was superior to the F80S05 and F80S10 columns, even when stirrup separation was greater. This took place because F80S30 had a 


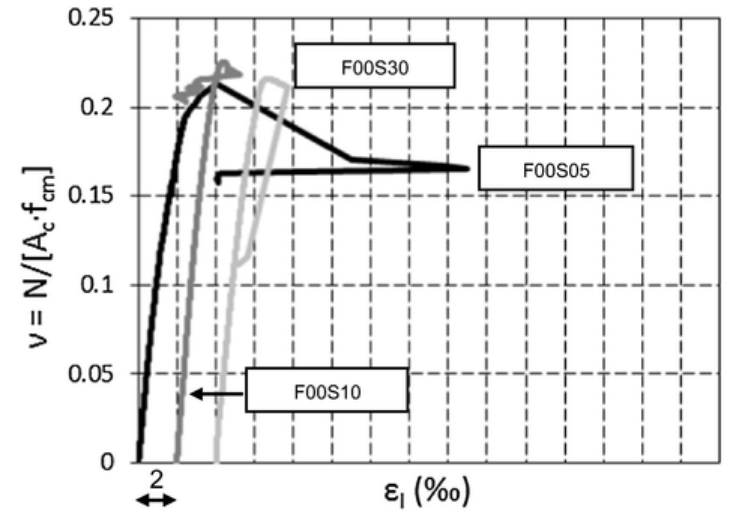

(a.1)

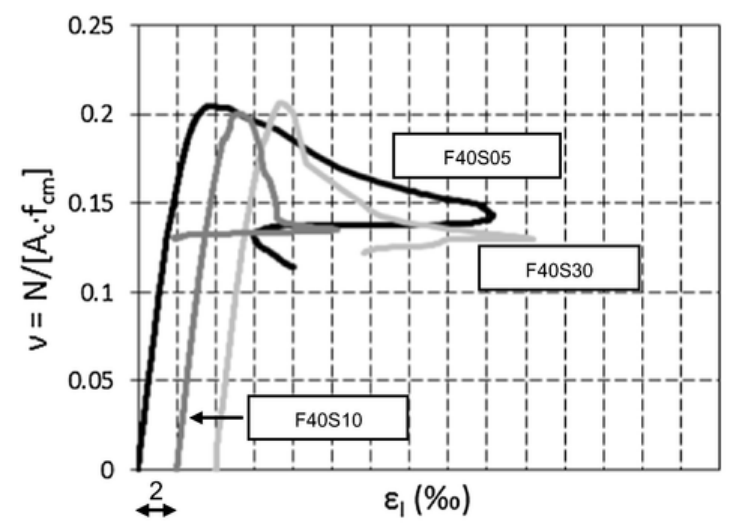

(b.1)

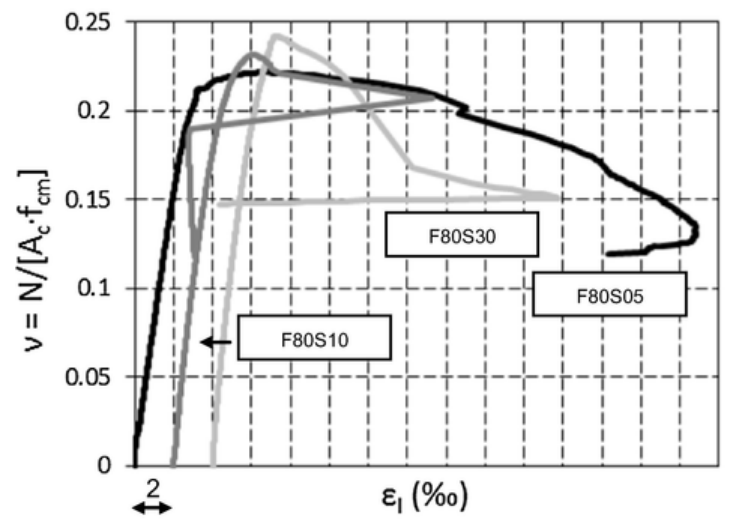

(c.1)
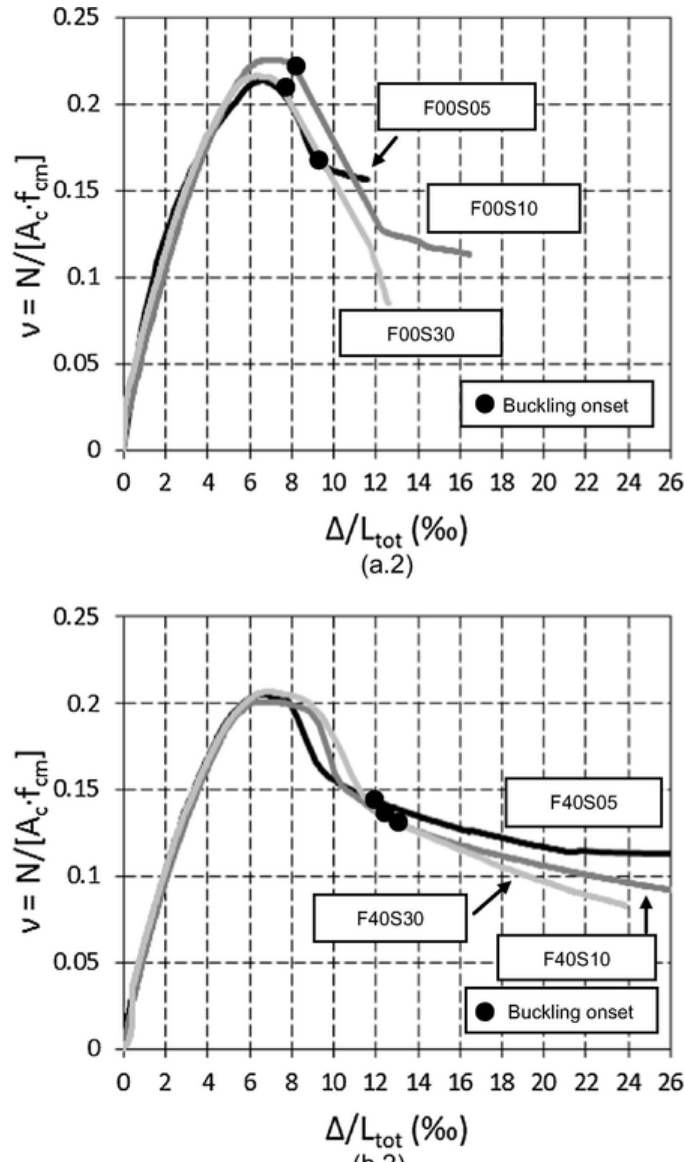

(b.2)

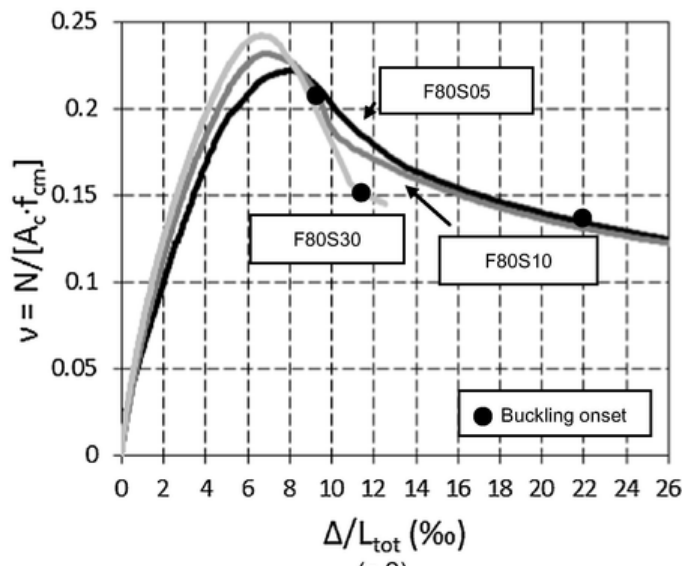

(c.2)

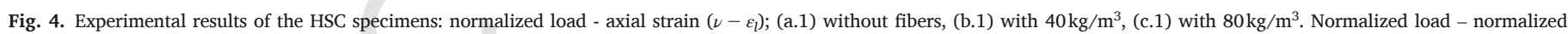
midspan displacement $\left(\nu-\Delta / L_{\text {tot }}\right)$ for the columns under eccentric loads, (a.2) without fibers, (b.2) with $40 \mathrm{~kg} / \mathrm{m}^{3}$, (c.2) with $80 \mathrm{~kg} / \mathrm{m}^{3}$.

different steel batch and the yield stress of tensile reinforcement was higher than in the other aforementioned specimens.

Regarding the post peak branch slope, we observed that the narrower stirrup separation was, the lower the absolute post-peak branch slope value became. A drop in the absolute post-peak branch slope value was observed when fiber content increased, and was lighter than in the FRNSC elements tested by Pereiro-Barceló and Bonet [2].

Specimen cracking patterns are shown in Fig. 5. For concrete without fibers, a plastic hinged was formed on the central support section. One or two wide tensile cracks was/were generated at the same time that the cover spalled and compressed reinforcement buckled (Fig. 5(a)). Cover spalling without progressive concrete degradation sud- denly occurred. This behavior has been observed by Collins et al. [37] and Leite et al. [38]. In concrete with fibers, the tensile cracking for service loads was more distributed with higher fiber content. However, in the failure state when plastic hinges were formed, only one wide crack opened in all cases (see Fig. 5(b) and (c)). The compressed zone cracking was longitudinal and more distributed with higher fiber content.

Table 4 shows the strain $\varepsilon_{\text {crit }}$ and buckling critical stress $\sigma_{\text {crit }}$ results. The latter was deduced from the constitutive stress-strain relation in compression. For the specimens without fibers, reinforcement buckling occurred after cover spalling, provided transverse reinforcement contained no buckling. This casuistry was undergone by specimens F00S10 
Table 4

The experimental campaign results and the comparison with the proposed model.

\begin{tabular}{|c|c|c|c|c|c|c|c|c|}
\hline \multirow[t]{3}{*}{ Specimens } & \multicolumn{6}{|c|}{ Experimental results } & \multicolumn{2}{|l|}{ Model results } \\
\hline & \multicolumn{2}{|l|}{ Peak load } & \multicolumn{4}{|c|}{ Instability situation of compressed bars } & \multicolumn{2}{|c|}{ Instability situation of compressed bars } \\
\hline & $\mathrm{N}_{\max }(\mathrm{kN})$ & $\Delta(\mathrm{mm})$ & $\mathrm{N}_{\mathrm{c}}(\mathrm{kN})$ & $\Delta_{\mathrm{c}}(\mathrm{mm})$ & $\varepsilon_{\text {crit }}(\% o)$ & $\sigma_{\text {crit }}(\mathrm{MPa})$ & $\varepsilon_{\text {crit,model }}(\% o)$ & $\sigma_{\text {crit,model }}(\mathrm{MPa})$ \\
\hline F00S05 & 685.88 & 0.91 & 533.12 & 13.00 & 10.16 & 557.46 & 4.21 & 550.18 \\
\hline F00S10 & 647.53 & 9.97 & 628.56 & 8.37 & 4.4 & 550.41 & 3.74 & 549.60 \\
\hline F00S30 & 708.11 & 8.72 & 691.72 & 10.40 & 4.5 & 550.53 & 4.61 & 550.66 \\
\hline F40S05 & 701.44 & 9.10 & 489.55 & 16.60 & 15.48 & 597.92 & 10.61 & 588.43 \\
\hline F40S10 & 683.70 & 9.18 & 460.96 & 17.10 & 7.06 & 584.42 & 9.71 & 587.19 \\
\hline F40S30 & 686.38 & 9.58 & 431.33 & 18.31 & 14.60 & 596.51 & 12.79 & 591.46 \\
\hline F80S05 & 699.17 & 11.06 & 422.84 & 30.48 & 26.9 & 645.98 & 10.61 & 588.43 \\
\hline F80S10 & 697.55 & 9.51 & 623.34 & 13.03 & 12.09 & 592.49 & 11.41 & 589.54 \\
\hline F80S30 & 776.41 & 9.34 & 485.09 & 15.89 & 16.36 & 565.04 & 13.78 & 561.89 \\
\hline
\end{tabular}

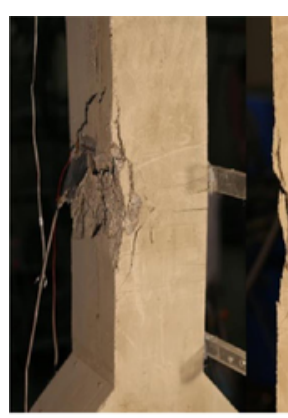

(a)

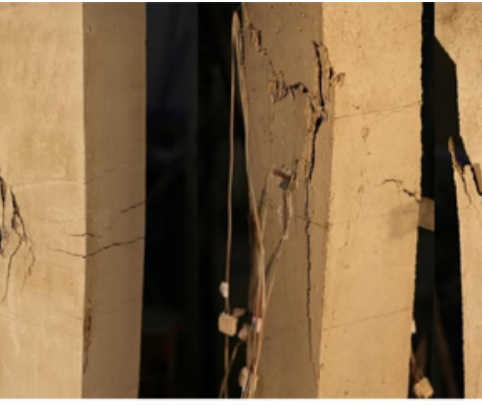

(b)

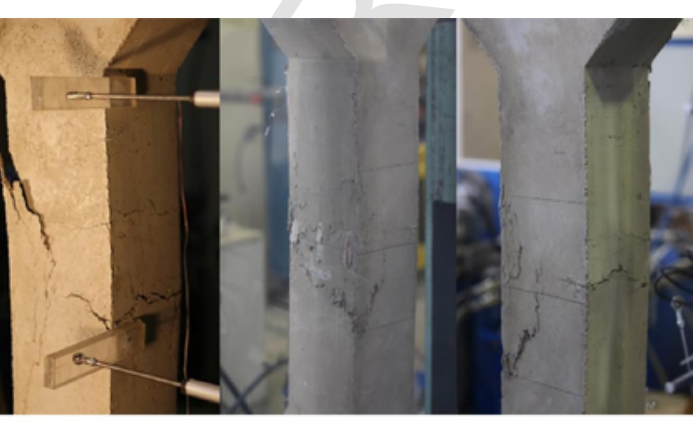

(c)

Fig. 5. Examples of the specimen state after the test, (a) HSC without fibers, (b) FRHSC with $40 \mathrm{~kg} / \mathrm{m}^{3}$, (c) FRHSC with $80 \mathrm{~kg} / \mathrm{m}^{3}$.

and F80S30. With F00S05, reinforcements buckled beyond cover spalling because transverse reinforcement was able to contain it. Cover spalling approximately took place when compressed reinforcement reached a strain of $\varepsilon_{c 85}$ (strain corresponded to a stress $0.85 \cdot f_{c m}$ after the peak load). This behavior has been observed by Campione [39] and by Pereiro-Barceló and Bonet [2] for elements made with normal strength concrete.

Regarding concrete with steel fibers, fibers augmented strain $\varepsilon_{\text {crit }}$ at which buckling took place (Table 4). Buckling was produced between stirrups $(\eta$ ? 1$)$ in the specimens with stirrup separations of $10 \mathrm{~cm}$ and $30 \mathrm{~cm}$ (F40S10, F40S30, F80S10 and F80S30), where $\eta=s / L, s$ the stirrup separation and $L$ the length of the region involved in instability; i.e., transverse reinforcement did not intervene in the buckling in these specimens. In the specimens with a stirrup separation of $5 \mathrm{~cm}$ (F40S05 and F80S05), transverse reinforcement delayed buckling.

\subsection{Calibrating cover concrete stiffness $\alpha_{c}$ and strain $\varepsilon_{c r i t, \eta \leq 1}$}

Once the experimental results had been obtained, the aim of this subsection was to extend the model of Pereiro-Barceló and Bonet [2], which was calibrated for NSC and FRNSC to consider elements HSC and FRHSC. Concrete cover $\alpha_{c}$ stiffness was calculated based on the experimental critical buckling stresses. To this end, the specimens in which the steel bar buckled between stirrups were used ( $\eta=L / s$ ? 1), i.e., those with a tie spacing of $10 \mathrm{~cm}$ and $30 \mathrm{~cm}$ were considered. Stiffness $\alpha_{c}$ (Expression (12)) was solved from Expressions (3) and (7).

$\alpha_{c}=\frac{\pi \sigma_{c r i t}^{2}}{3 E_{r}}$

where: $\sigma_{\text {crit: }}$ Experimental critical buckling stress

$E_{r}$ : The reduced modulus of the longitudinal bar proposed by Papia et al. [5] or with Expression (11)

Fig. 6 shows values $\alpha_{c}$ and $\varepsilon_{c r i t, \eta ? 1}$. The results of the FRNSC specimens tested by Pereiro-Barceló and Bonet [2] with $\eta ? 1$ are also displayed. The yield stress of the compressed bars was 545MPa. Once again, a constant $\alpha_{c}$ value of $70 \mathrm{MPa}$ can be observed. This value was independent of $f_{R, 1}$ (Fig. 6). A new expression for determining strain $\varepsilon_{c r i t, \eta ? 1}$ until stiffness $\alpha_{c}$ was guaranteed was proposed (Expression (13)), and was valid for NSC, FRNSC, HSC and FRHSC. In this expression, $\varepsilon_{c r i t, \eta ? 1}$ is expressed in $\% o$ and $f_{R, 1}$ in MPa. Expression (13) is simi-

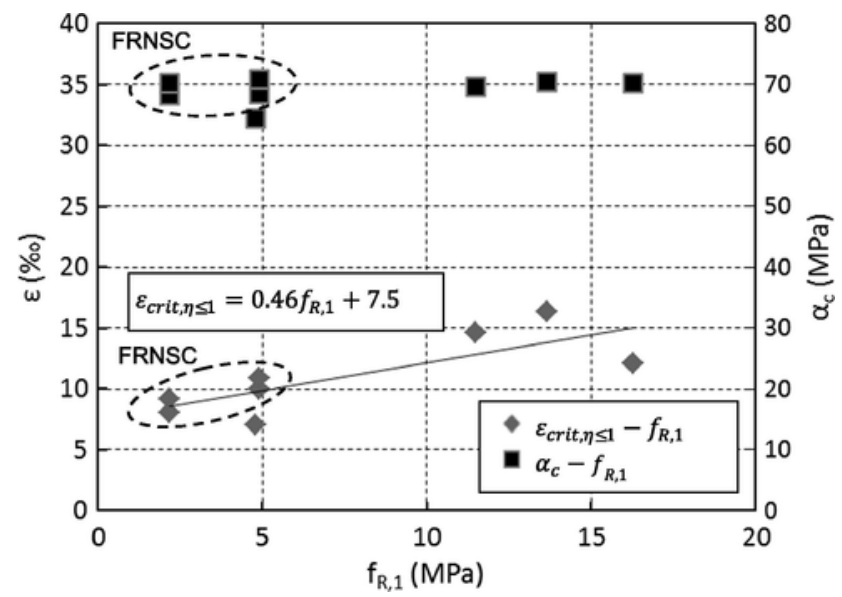

Fig. 6. Compressed bar strain in the instability situation $\left(\varepsilon_{c r i t, n \leqslant 1}\right)$ - residual tensile strength $f_{R, 1}$ (left); concrete cover stiffness $\alpha_{c}$ - residual tensile strength $f_{R, 1}$ (right). 
lar to that proposed by Pereiro-Barceló and Bonet [2] for FRNSC (Expression (2)). The linear behavior of $\varepsilon_{c r i t, \eta ? 1}-f_{R, 1}$ was maintained for FRHSC. Fig. 6 also shows the values of $\varepsilon_{\text {crit, } \eta \text { ? } 1}$ in relation to $f_{R, 1}$.

$$
\varepsilon_{c r i t, \eta \leqslant 1}(\% o)=0.46 f_{R, 1}(\mathrm{MPa})+7.5
$$

Theoretically, buckling critical load determinations through an analytic model involve to find the intersection of the critical buckling line of the bar with the pure stress-strain curve of the material under compression [12]. As Fig. 7 shows, depending on steel quality, the critical buckling line intersected the steel constitutive curve at different points. This means that buckling stress was distinct and, consequently, distinct $\alpha_{c}$ values were obtained from Expression (12).

In this research, the compressive behavior of steel reinforcements was analyzed, whose yield stresses were between 545 and $575 \mathrm{MPa}$ (Table 3). It is important to point out that despite different steel qualities being used in this research, no significant differences in the $\alpha_{c}$ value were found. These differences were not significant because of the inherent dispersion of the results of this type of experimental tests, and also because of a small difference in qualities.

It is noteworthy that it was only possible to adopt the $\alpha_{c}$ value that differed from zero if cover thickness was sufficient for fibers to sew the reinforcement to the core. Besides, concrete strengths $f_{R, 1}$ and $f_{R, 3}$ could not go below $40 \%$ and $20 \%$ of the proportionality limit $\left(f_{L O P}\right)$, respectively, for fibers to have a structural function (EHE-08 [22]).

With fiber-reinforced concrete elements, the intersection between the critical buckling line and the steel stress-strain curve under compression was on the plastic branch $\left(\varepsilon_{y, c}<\varepsilon_{c r i t, \eta ? 1}\right)$. Critical stress was higher than steel compressed yield stress $\left(f_{y, c}\right)$. Consequently, a lower level of cover stiffness $\left(\alpha_{c, \text { inf }}\right)(14)$ was obtained based on Expression (12). $\alpha_{c, \text { inf }}$ was limited to $70 \mathrm{MPa}$ of security because it was the maximum stiffness achieved in the experimental tests.

$\alpha_{c, \text { inf }}=\frac{\pi f_{y, c}^{2}}{3 E_{r}} \ngtr 70$ (in $\mathrm{MPa}$ )

If steel was of less quality than the reference one (Fig. 8), the critical load of the compressed bar would be theoretically higher than the reference one, provided the concrete cover was not inefficient. Thus for a steel whose quality was lower than the reference one, by considering that the critical strain equaled $\varepsilon_{c r i t, \eta ? 1}$ (Expression (13)), it was on the security side. Bar critical stress was associated with $\varepsilon_{c r i t, \eta ? 1}$ ( $\left.\sigma_{\text {crit }}=\sigma_{s}\left(\varepsilon_{\text {crit }, \eta \leqslant 1}\right)\right)$.

Nevertheless for higher quality steels than the reference one (Fig. 9), it was not possible to use the critical strain value of $\varepsilon_{\text {crit, } \eta \text { ? } 1}$ because the actual critical strain that corresponded to the intersection between the critical line and the constitutive curve was lesser than $\varepsilon_{c r i t, \eta ? 1}$. Besides, critical stress $\sigma_{\text {crit }}$ was higher than the yield stress of steel under

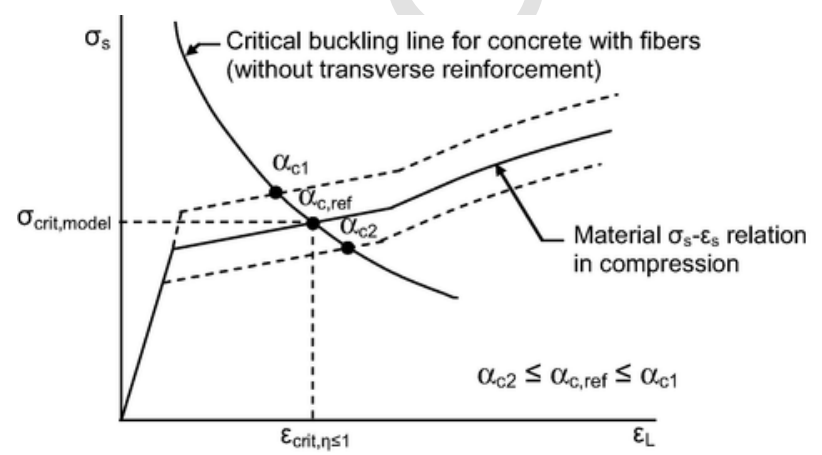

Fig. 7. Determination of cover stiffness $\alpha_{c}$ according to steel quality.

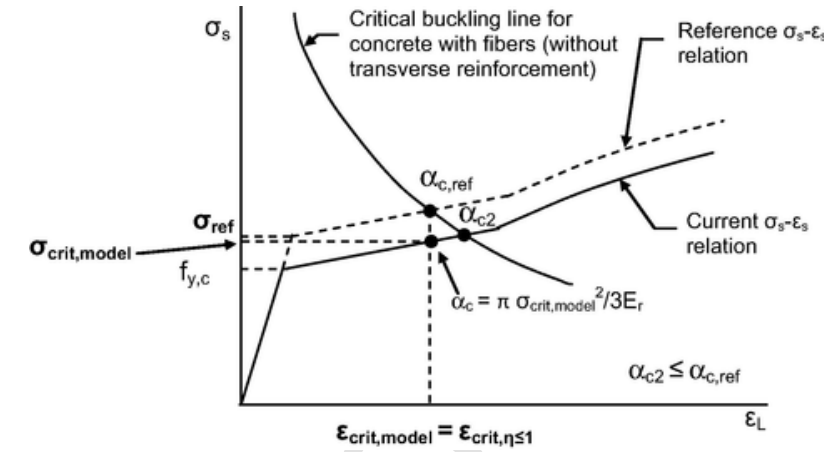

Fig. 8. Critical stress calculation for less quality steels than the reference ( $\eta$ ?1).

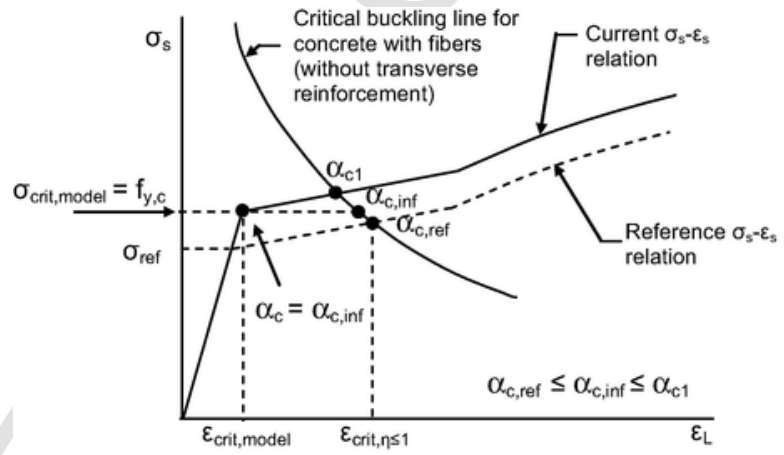

(a)

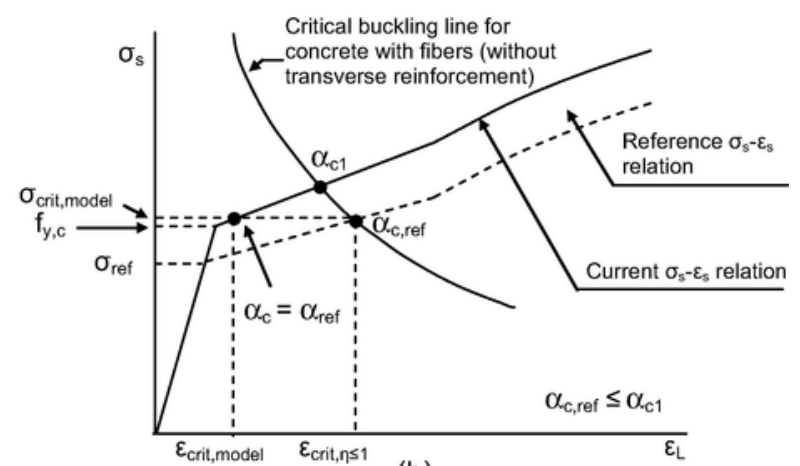

(b)

Fig. 9. Critical stress calculation for higher quality steels than the reference ( $\eta$ ?1): (a) Steel with a low plastic modulus (b) Steel with a high plastic modulus.

compression since the plastic branch slope was not zero [33]. In this case, $\alpha_{c}=\alpha_{c, \text { inf }}$ (Expression (14)) was on the security side.

The steel with a yield stress of $575 \mathrm{MPa}$ was chosen as the reference steel ( $\left.\sigma_{r e f}=575 \mathrm{MPa}\right)$ since, as stated before, greater restrictions to the buckling critical strain values occurred in better quality steels than those of the reference one. The reference concrete cover stiffness was $\alpha_{c, r e f}=70 \mathrm{MPa}$, which was guaranteed up to longitudinal bar strains $\left(\varepsilon_{l}\right.$ ) that equaled $\varepsilon_{\text {crit, } \eta ? 1}$ (13) for both the buckling between stirrups ( $\eta$ ?1) and otherwise $(\eta>1)$.

The results of critical strain $\left(\varepsilon_{\text {crit,model }}\right)$ and critical stress ( $\left.\sigma_{\text {crit,model }}\right)$ are shown in Table 4 . These results were obtained by applying the analytical model with the recalibrated values of $\alpha_{c}$ and $\varepsilon_{c r i t, \eta ? 1}$ to take into account the NSC and HSC elements both with and without fibers. In all the tested specimens, buckling strain was always lower than the strain at which steel entered the hardening branch $\left(\varepsilon_{s h}\right)$. Consequently, the hypothesis to assume a zero plastic modulus of the steel bars under tension, which was adopted to deduce Expression (11), was valid. The dilatancy criterion proposed by Lokuge et al. [29] was used to determine 
the transverse strain from the longitudinal strain and to establish, therefore, if stirrups were yielded. The results of the minor small variations in the tie spacing in the specimens with stirrup separations of $5 \mathrm{~cm}$ displayed high sensitivity. This was why the results of these specimens (Table 4) differed from the experimental results. However, if a separation of $4.8 \mathrm{~cm}$ was introduced into the analytical model, it gave similar results to the experimental ones. These values also fell within the specimen fabrication tolerances.

\section{Design recommendations}

The goal of this section was to propose design recommendations for the required tie spacing in concrete elements with and without fibers to delay compressed reinforcement buckling. These recommendations are based on experimental observations (Section 3.5), and on applying the analytical model explained in Section 2.1 and recalibrated in Section 3.6 to consider HSC and FRHSC. The design recommendations for tie spacing depend on the adopted design criterion: achieving either reinforcement yield stress (stress criterion) or a determined strain (strain criterion).

\subsection{Design recommendation for calculating tie spacing in reinforced concrete elements without fibers to delay local buckling}

For RC elements without fibers, experimental work [2,39] have determined that the concrete cover spalls for a longitudinal strain $\varepsilon_{L}$ of the bar above $\varepsilon_{c, 85}$. If this happens, then $\alpha_{c}=0$. Consequently, the con- sideration that the concrete cover spalled from the beginning on the security side was proposed.

Before proposing a design recommendation, it was necessary to use simplified expressions to determine the critical buckling stress that resulted from applying the mixed model (Sections 2 and 3.6) for concrete without fibers by considering different transverse reinforcement separations $s$ and distinct transverse and longitudinal reinforcement diameters ( $\phi_{t}$ and $D$, respectively). The results obtained in a specific case are shown in Fig. 10, where a diagram with three graphs is shown: stress strain (quadrant A), tie spacing - strain (quadrant B) and longitudinal reinforcement diameter - tie spacing (quadrant $C$ ). The intersections of the horizontal critical buckling lines with the constitutive line in quadrant A define the buckling stress and strain for each tie spacing $s$. The critical buckling lines were obtained by applying Expression (3), with $\alpha_{c}=0$, with different values of either the longitudinal reinforcement modulus (elastic $\left(E_{s}\right)$ or the reduced modulus $\left(E_{r}\right)$ ), and with distinct values for transverse reinforcement stiffness $\alpha_{s}$, (elastic $\left(\alpha_{s, e}\right)$ or yielding $\left(\alpha_{s, y}\right)$ ). Consequently for concrete without steel fibers, three horizontal lines were found: the first with the elastic stiffness of compressed bars $\left(E_{s}\right)$ and with transverse reinforcement stiffness without yielding ( $\left.\alpha_{s}=\alpha_{s, e}\right)$; the second with a reduced modulus of compressed bars $\left(E_{r}\right)$ and $\alpha_{s}=\alpha_{s, e}$; and the third line that considered $E_{r}$ and yielded transverse reinforcement stiffness $\left(\alpha_{s}=\alpha_{s, y}\right)$.

In quadrant $\mathrm{A}$, the application of the simplified expressions that resulted from a mixed model (Sections 2 and 3.6) is shown for a longitudinal bar with a diameter of $20 \mathrm{~mm}$ (D), a transverse reinforcement diameter $\left(\varnothing_{\mathrm{t}}\right)$ of $8 \mathrm{~mm}$, and different transverse reinforcement separations $s$ (from 5 to $30 \mathrm{~cm}$ ). For the separations between 5 and $7 \mathrm{~cm}$, the

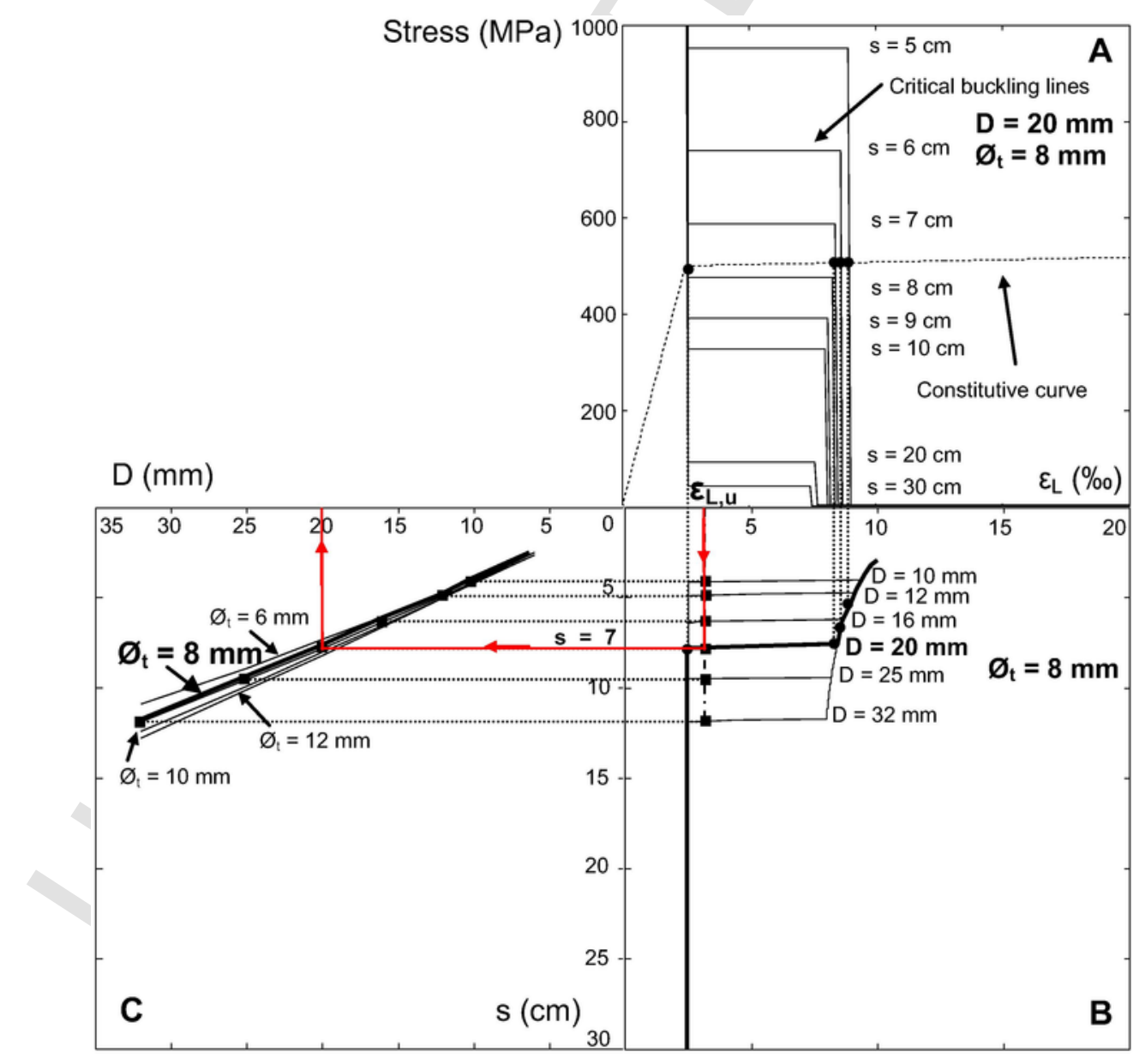

Fig. 10. Analytical model applied to concretes without fibers. 
bar buckles when stirrups yield (see the drop in the critical line). The lesser the separation, the more bar buckling stress and strain. As it is well-known, the lesser the stirrup separation, the more confinement and, according to Lokuge et al. [29], the dilatancy coefficient becomes lower. Consequently, transverse reinforcement yields for a higher longitudinal strain. However, for higher separations, the critical line dramatically diminished in the strain at which reinforcement yielded under compression $\varepsilon_{y, c}$. This happened because the elasticity modulus used to calculate critical stress was $E_{s}$ for any strains lower than $\varepsilon_{y, c}$, and $E_{r}$ for higher strains. When the model was systematically applied to several longitudinal reinforcement diameters, the strain - separation of the transverse reinforcement diagram was obtained, and can be consulted in Fig. 10, quadrant B. The curve obtained for a longitudinal reinforcement diameter of $20 \mathrm{~mm}$ and for a transverse reinforcement of $8 \mathrm{~mm}$ is highlighted on a thicker line.

Finally, when the curves in the B quadrant were intersected with the required ultimate strain for compressed bars $\left(\varepsilon_{L, u}\right)$, the longitudinal bar diameter - the separation of transverse reinforcement curve was obtained (see Fig. 10, quadrant $\mathrm{C}$ ). The curve obtained for a transverse reinforcement of $8 \mathrm{~mm}$ diameter is highlighted with a thicker line. When this process was followed for several transverse reinforcement diameters, all the other curves in Fig. 10, quadrant C, were obtained. Next some important aspects in Fig. 10 are highlighted:

- On the curves of the B quadrant, the buckling strains sharply decreased. This variation happened when the critical line of quadrant A intersected the steel constitutive curve at either the strain at which longitudinal reinforcement yielded $\varepsilon_{y, c}$ or the longitudinal strain at which transverse reinforcement yielded $\varepsilon_{L, w y}$. The former occurred when the critical stress of bar $\sigma_{\text {crit }}$, which was calculated with stirrups elastic stiffness $\left(\alpha_{s}=\alpha_{s, e}\right)$ and with modulus $E_{r}$, was lower than the bar yield stress $\left(\sigma_{c r i t} ? f_{y, c}\right)$. The second occurred when stirrups yielded $\left(\alpha_{s}=\alpha_{s, y}\right)$, which implied a drop in the critical line of the compressed bar.

- In order to generate the curves of quadrant $C$, the required ultimate strain that the bar was expected to achieve without buckling $\varepsilon_{L, u}$ had to be defined. This strain can be defined by a stress criterion $\left(\sigma_{\text {lim }}\right)$ or by a strain criterion $\left(\varepsilon_{L, u}\right)$. Both criteria are related by means of the constitutive equation of the compressed bar (Expression (15)):

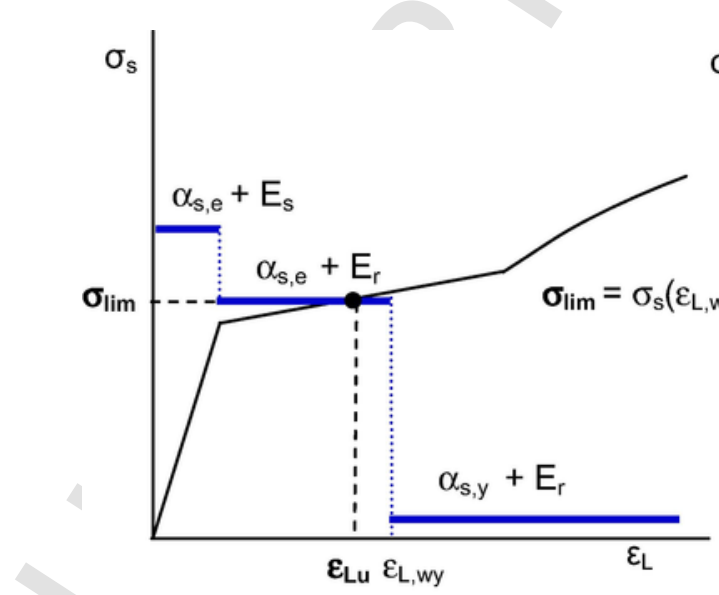

(a) $\sigma_{\text {lim }}=\left\{\begin{array}{c}E_{h, c}\left(\varepsilon_{L, u}-\varepsilon_{y, c}\right)+f_{y, c} \text { if } \varepsilon_{L, u}>\varepsilon_{y, c} \\ E_{S} \varepsilon_{L, u} \text { if } \varepsilon_{L, u} \leqslant \varepsilon_{y, c}\end{array}\right.$

where:

$\varepsilon_{y, c}$ : The yield strain of compressed reinforcement $\varepsilon_{y, c}=f_{y, c} / E_{s}$

$f_{y, c}$ : The yield stress of steel under compression

$E_{h}$ : Plastic modulus under compression

- By taking into account the two previous points, an adequate design criterion to know the required tie spacing was that the horizontal critical line in quadrant A coincided with a required limit stress $\sigma_{\text {lim }}$. In other words, critical buckling stress $\sigma_{\text {crit }}$ had to equal a predefined limit required stress $\sigma_{\text {lim }}\left(\sigma_{\text {crit }}=\sigma_{\text {lim }}\right)$. Following this criterion, an expression of transverse separation $s$ from the analytical model was obtained, as explained below.

For concrete without fibers, the concrete cover was considered to have spalled on the security side. Therefore, adimensional critical stress $c_{c}$ was calculated from Expression (4) for $k_{c s}=0$. If Expression (4) was substituted in (3) and $\sigma_{\text {crit }}=\sigma_{\text {lim }}$ was stated, then the expression to calculate the required tie spacing $s$ could be obtained (Expression (16)).

$s=\frac{\pi D}{2} \sqrt{\frac{E_{r}}{\sigma_{\lim }}\left(1-\frac{1}{1+0.09\left(\frac{64 \alpha_{s} s^{3}}{\pi E_{r} D^{4}}\right)^{0.58}}\right)}$

Expression (16) depicts how the separation is related directly to reduced modulus $E_{r}$ and inversely to yield stress $\sigma_{\text {lim }}$. This expression requires a simple iterative calculation because it is an implicit function. If the bar should not buckle for lower stresses than the yield stress (the stress criterion), then the required limit stress $\sigma_{\text {lim }}$ must be substituted for the required stress, which is not higher than the yield stress $\left(\sigma_{\text {lim }} ? f_{y, c}\right.$ ), and the reduced modulus must be substituted for the elastic modulus $\left(E_{r}=E_{s}\right)$. If ultimate strain $\varepsilon_{L, u}$ needs to be higher than the yield strain of the compressed bar $\left(\varepsilon_{y, c}=f_{y, c} / E_{s}\right)$ (the strain criterion), then reduced modulus $E_{r}$ can be calculated more simply with Expression (11) and the following steps must be followed (Fig. 11.a): (1) Calculate the strain of the compressed bar at which stirrups are yielded

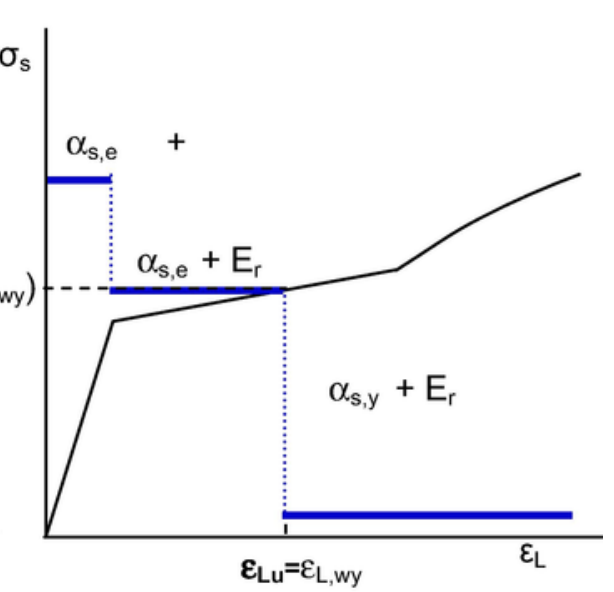

(b)

Fig. 11. Calculating tie spacing in elements without steel fibers: (a) Transverse reinforcement without yielding, (b) Proposal of a definition of required limit stress $\sigma_{\text {lim }}$ for $\varepsilon_{L u}=\varepsilon_{L, w y}$. 
$\varepsilon_{L, w y}$ by using the dilatancy coefficient [29]; (2) If $\varepsilon_{L, u}$ is lower than $\varepsilon_{L, w y}$, elastic stirrups stiffness is used $\left(\alpha_{s}=\alpha_{s, e}\right)$, otherwise the yielded stiffness is used $\left(\alpha_{s}=\alpha_{s, y}\right)$; (3) Assess the compression stress that corresponds to strain $\varepsilon_{L, u}(15)$ and state that $\sigma_{\text {crit }}=\sigma_{\text {lim }}$; (4) Finally, calculate separation $s$ from Expression (16).

Although it is theoretically possible to apply this methodology to required ultimate strains $\varepsilon_{L, u}$ that are superior to the longitudinal strain for which the stirrups yield $\varepsilon_{L, w y}$, it makes no sense from a practical viewpoint for the following reasons: (1) In elements fabricated with concrete without steel fibers, it is difficult for the strain of the compressed bar to exceed strain $\varepsilon_{L, w y}$, whose order of magnitude is between 6 and $10 \%$; (2) When stirrup stiffness significantly reduces (from elastic $\alpha_{s, e}$ to $\alpha_{s, y}$ ). Like the order of magnitude, elastic stiffness $\alpha_{s, e}$ lies between 50 and $5000 \mathrm{MN} / \mathrm{m}$, whereas plastic stiffness $\alpha_{s, y}$ varies from 0.1 to $5 \mathrm{MN}$ / $\mathrm{m}$. This reduction implies that the tie spacing calculated by applying Expression (16) is very low, which would cause problems for cast-in-place concrete.

The limit situation of a minimum required separation of transverse reinforcement with the elastic stiffness of stirrups $\left(\alpha_{s}=\alpha_{s, e}\right)$ occurred when the predefined ultimate strain required for the bar without buckling $\varepsilon_{L, u}$ equaled the longitudinal bar strain at which stirrups yielded, $\varepsilon_{L, w y}$ (Fig. 11.b). In this case, it would be possible to ensure that compressed reinforcement would not buckle, provided stirrups did not yield.

Fig. 12 represents the tie spacing obtained from Expression (16) for the steel bars with $f_{y, c}: 400,500$ and $600 \mathrm{MPa}$ and for a range of stiffnesses of stirrups $\alpha_{s}$ between 50 and $5000 \mathrm{MN} / \mathrm{m}$. The minimum sepa-

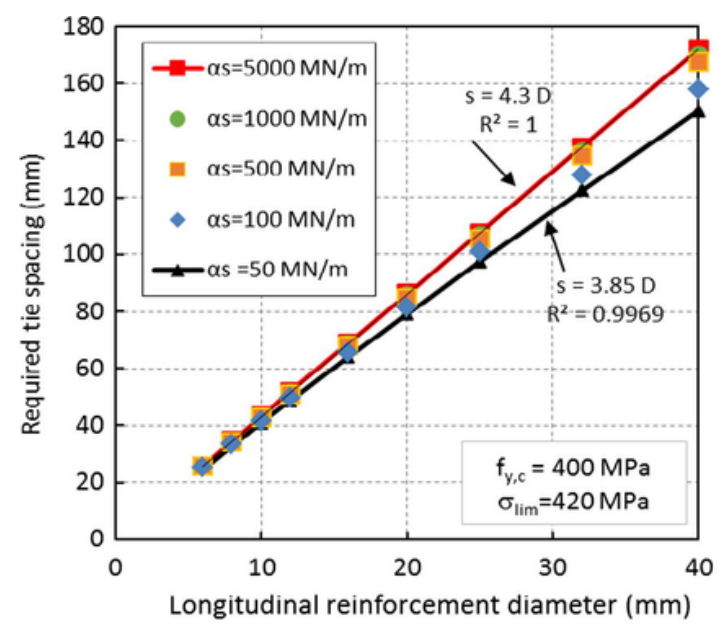

ration criterion was applied to ensure that stirrups did not buckle before transverse reinforcement yielding (Fig. 11b). As buckling occurred on the plastic branch, reduced modulus $E_{r}(11)$ was used. It was assumed that an upper level of the yield stress of stirrups $\sigma_{s}\left(\varepsilon_{L, w y}\right)$ equaled $1.05 \cdot f_{y, c}$ on the security side. Therefore, the required limit stresses $\sigma_{\text {lim }}$ were 420,525 and $630 \mathrm{MPa}$. This implied a value of $\varepsilon_{L, w y}$ of approximately $25 \%$ o when taking the constitutive curve under compression stated by Dodd and Restrepo [33] as a reference. Tie spacing did not significantly vary with the variation in required ultimate strain $\varepsilon_{L, u}$ because the associated required limit stress $\sigma_{\text {lim }}$ only slightly altered due to the plastic branch low slope. Only sudden changes were observed if stirrups yielded; i.e., if $\alpha_{s}=\alpha_{s, e}$ or $\alpha_{s}=\alpha_{s, y}$ was used (Fig. 11). In Fig. 12 , as expected, separation was greater when limit stress $\sigma_{\text {lim }}$ diminished and transverse reinforcement stiffness $\alpha_{s}$ was higher. We also observed that a linear approach was adequate. The differences in both the required minimum separation for the required limit stresses and the studied transverse reinforcement stiffnesses were not that important from a practical point of view to propose an expression for stirrup separation. This proposal was 4 times the diameter of longitudinal reinforcement ( $s=4 D$ ) to assure that the compressed bars did not buckle before stirrups yielded.

Fig. 13 represents the required tie spacing obtained from Expression (16) using a stress criterion if the bar is not to buckle before achieving yield stress $\left(\sigma_{\text {lim }} ? f_{y, c}\right)$. A yield stress $\sigma_{\text {lim }}$ of $500 \mathrm{MPa}$ was taken and, therefore, the reduced modulus equaled the elasticity modulus $\left(E_{r}=E_{s}\right)$. As expected, transverse separation increased with stirrups stiffness. A linear approach was adequate and no major variation in the

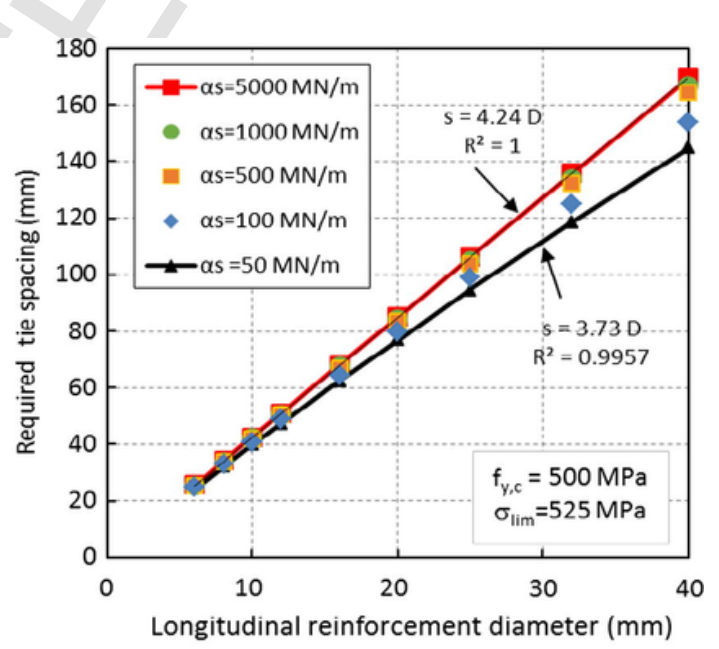

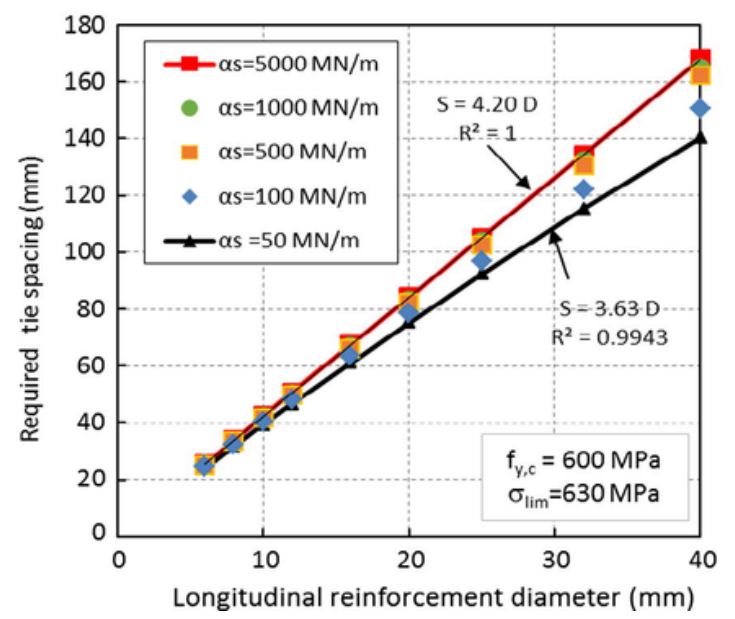

Fig. 12. Example of the required minimum separation using $E_{r}$ : (a) $f_{y, c}=400 \mathrm{MPa}$; (b) $f_{y, c}=500 \mathrm{MPa}$; (c) $f_{y, c}=600 \mathrm{MPa}$. 


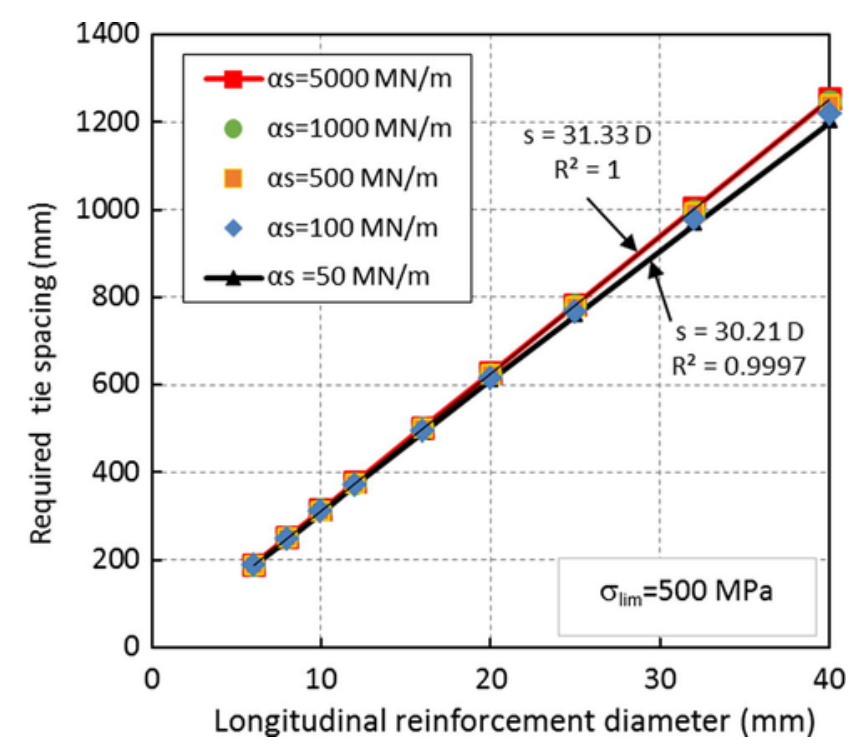

Fig. 13. Example of the required separation using $E_{s} . \alpha_{s}$ units are in $\mathrm{MN} / \mathrm{m}$.

results occurred as regards the stiffness of stirrups $\alpha_{s}$. From a practical point of view, a separation between stirrups of 30 times the longitudinal reinforcement diameter $(s=30 D)$ was proposed.

\subsection{Comparison with existing codes}

This section compares the maximum tie spacings that the codes provide to those ones obtained with Expression (16). The analyzed codes were: EHE-08 [22], EC-2 [34], new proposal of EC2 [40], MC 2010 [41], ACI 318 [25] and EC8 [23]. Table 5 shows the maximum code tie spacings, where $\phi_{t}$ respectively is the transverse reinforcement diameter, $s$ is tie spacing and $D$ is the longitudinal reinforcement diameter.

Fig. 14 represents the relationship between the required tie spacing and the longitudinal reinforcement diameter (D) that correspond to the design code limits.

Fig. 14 shows significant differences between the codes, which can be divided into two groups. The first group would correspond to those codes that propose tie spacing to assure that reinforcement does not buckle before accomplishing yield stress (EC-2 [34], EHE-08 [22], MC 2010 [41] and the new proposal of EC2 [40]). These recommendations are based on a stress criterion. In this group, the separations from 9D to $20 \mathrm{D}$ are proposed. A second group includes those codes that have to assure that reinforcement does not buckle after concrete cover spalling (ACI 318 [25] and EC8 [23]). In this case, bars are expected to accomplish a strain beyond the yield strain without buckling (strain criterion). In this group, the separations from 6D to 8D are proposed. Fig. 14 also shows the results obtained by applying the proposed Expression (16). The same parameters as those shown in Fig. 12 for the strain criterion were used, along with those displayed in Fig. 13 for the stress criterion. In Fig. 14, the black markers indicate the results according to the stiffness of stirrups $\alpha_{s}$. Therefore when varying $\alpha_{s}$, no significant changes in tie spacing took place for the $50-5000 \mathrm{MN} / \mathrm{m}$ range (elastic stiffness $\alpha_{s}=\alpha_{s, e}$ ). As mentioned above, the required separations of the transverse reinforcement of 4D for the strain criterion and 30D for the stress criterion proved adequate.

When comparing the results from Expression (16) (30D and 4D) with the codes, the proposal was placed above the codes when applying a criterion based on stresses, and behind them when a strain criterion was applied. It was experimentally observed in both the experimental results of the present research and others $[26,27]$ that bars buckled with a $6 \mathrm{D}$ separation, while transverse reinforcement was able to delay reinforcement buckling sufficiently with a 4D separation.

\subsection{Design recommendations for calculating the required tie spacing in fiber-reinforced concrete elements to delay local buckling}

This section aimed to propose an expression to calculate tie spacing by taking into account the effect of a fiber-reinforced concrete cover.

Similarly to concretes without fibers, a criterion based on stresses or strains was used to determine the required tie spacing. In the first criterion, critical stress $\sigma_{\text {crit }}$ equaled the predefined limit stress $\sigma_{\text {lim }}$. The fact that the bar did not buckle before achieving yield stress $\left(\sigma_{\text {lim }}=f_{y, c}\right)$ can be applied. In the second criterion, required ultimate strain $\varepsilon_{L u}$ was defined, which was related to the required limit stress $\sigma_{\text {lim }}$ by means of the constitutive equation of the compressed bar (Expression (15)). Similarly to the previous criterion, critical stress $\sigma_{\text {crit }}$ equaled the required limit stress $\sigma_{\text {lim }}$ associated with $\varepsilon_{L u}$. As observed experimentally in former works $[2,26,27,42]$, steel fibers delayed the buckling of bars. For this reason, a strain criterion was applied. For those steels whose yield stress $f_{y, c}$ was lower than the reference stress of analytical model $\sigma_{r e f}$, strain $\varepsilon_{L u}$ equaled strain $\varepsilon_{c r i t, \eta ? 1}$ (Expression (13)). However, for those steels whose yield stress $f_{y, c}$ was higher than reference stress $\sigma_{\text {ref }}$ (Fig. 9), guaranteeing that strain $\varepsilon_{c r i t, \eta ? 1}$ would be achieved was not possible. In this case, strain $\varepsilon_{L u}$ equaled the maximum strain guaranteed by the model $\left(\varepsilon_{\text {crit,model }}\right)$ which, for those steels with a low plastic modulus $E_{h}$ (Fig. 9 (a)), equaled the yield strain of the steel in compression $\left(\varepsilon_{L u}=\varepsilon_{y, c}=f_{y, c} / E_{s}\right)$. Otherwise (Fig. 9 (b)), it equaled the strain associated with the required limit stress of the model $\left(\varepsilon_{L u}=\frac{\sigma_{\mathrm{lim}}-f_{y, c}}{E_{h, c}}+\varepsilon_{y c}\right)$ from Expression (15). The required limit stress $\sigma_{\text {lim }}$ (17) was obtained by substituting Expression (7) in Expression (3) for a cover stiffness of $\alpha_{c}=\alpha_{\text {ref }}=70 \mathrm{MPa}$. Stress $\sigma_{\text {lim }}$, which was calculated in Expression (17), took a lower level on the security side because it considered $\alpha_{s}=0$. If $\alpha_{s}$ was considered, required limit stress $\sigma_{\text {lim }}$ would be obtained by substituting Expressions (5) or (6) in Expression (3).

$\sigma_{\text {lim }} \geqslant \sqrt{\frac{3 E_{r} \alpha_{r e f}}{\pi}} \nless f_{y, c}$

where:

$E_{r}$ : Reduced modulus if $\varepsilon_{L u}>\varepsilon_{y, c}$ or elasticity modulus if $\varepsilon_{L u}=\varepsilon_{y, c}$. Strain $\varepsilon_{L u}$ was obtained by substituting $\sigma_{\text {lim }}$ in Expression (15).

Finally, required tie spacing (18) was determined from Expression (3). Expression (18) required a simple iterative calculation because $c_{c}$

Table 5

Required tie spacing according to the codes.

\begin{tabular}{|c|c|c|c|c|c|c|c|c|c|c|}
\hline & \multirow[t]{2}{*}{ EHE-08 [22] } & \multicolumn{2}{|c|}{ EC-2 [34] } & \multicolumn{2}{|c|}{ EC2 Proposal [40] } & \multirow[t]{2}{*}{ MC 2010 [41] } & \multicolumn{2}{|c|}{ ACI 318 [25] } & \multicolumn{2}{|c|}{ EC8 [23] } \\
\hline & & Rest & Critical & Rest & Critical & & Ordinary & Special & DCM & $\mathrm{DCH}$ \\
\hline$\phi_{\mathrm{t}}(\mathrm{mm}) \geq$ & 3 & 6 & 6 & 6 & 6 & - & - & - & 6 & 6 \\
\hline $\mathrm{s}(\mathrm{cm}) \leq$ & 15.D & $20 \cdot \mathrm{D}$ & 12.D & 15.D & 9.D & 15·D & 8.D & 6.D & 8.D & 6.D \\
\hline
\end{tabular}




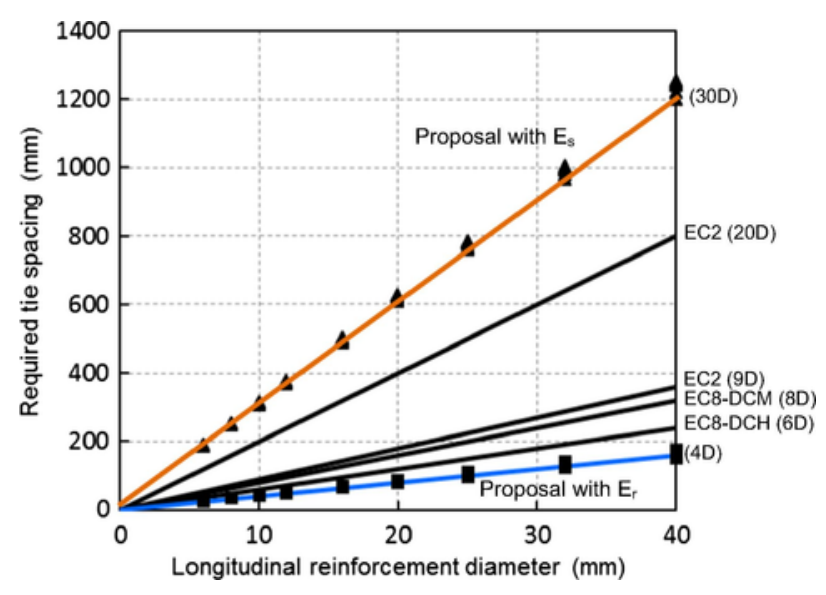

Fig. 14. Required tie spacing. Comparison between the codes and the proposal.

depended on separation $s$.

$s=\frac{\pi D}{\pi} \sqrt{\frac{E_{r} c_{c}}{\sigma_{\text {lim }}}}$

Table 6 displays the procedure to obtain the required limit stresses and strains $\left(\sigma_{\text {lim }}, \varepsilon_{L u}\right)$ depending on the chosen criterion (stress or strain). Stiffnesses $\alpha_{c}$ and $\alpha_{s}$ are also shown. The yielded stiffness of transverse reinforcement was considered to be zero $\left(\alpha_{s, y}=0\right)$.

Fig. 15 displays tie spacing depending on the longitudinal reinforcement diameter for the different $\alpha_{s}$ values. The yield stress of longitudinal steel is $\sigma_{r e f}=575 \mathrm{MPa}$ and the adopted required limit stress is $\sigma_{\lim }=1.05 \cdot f_{y, c}=604 \mathrm{MPa}$. When $\alpha_{s}$ increases, tie spacing also increases for a given diameter of longitudinal reinforcements. Tie spacing significantly changes when varying the stiffness of stirrups $\alpha_{s}$, conversely to what happened for plain concretes (Fig. 14).

As previously discussed, the longitudinal strain in which transverse reinforcement yield $\varepsilon_{L, w y}$ was between 6 and $10 \%$. Therefore given the experimental results (Table 4), the local buckling of the longitudinal bar took place when transverse reinforcement was yielded $\left(\alpha_{s}=\alpha_{s, y} \approx 0\right)$. Thus for these cases, transverse reinforcement was unable to delay longitudinal bar buckling.

Another noteworthy aspect is that stiffness $\alpha_{c}=70 \mathrm{MPa}$ was guaranteed when the stress criterion was considered $\left(\varepsilon_{L u} ? \varepsilon_{y, c} ? \varepsilon_{c r i t, \eta ? 1}\right)$. The minimum critical stress of the bar, which was obtained by neglecting stirrups stiffness ( $\alpha_{s}=0$ ), equaled $3656 \mathrm{MPa}$. Consequently when using a stress criterion where $\sigma_{\text {lim }}=f_{y, c}$ in the elements made with concrete with fibers, no transverse reinforcement was required to prevent reinforcement buckling.

When a strain criterion was applied $\left(\varepsilon_{y, c} ? \varepsilon_{L u} ? \varepsilon_{c r i t, \eta ? 1}\right)$, it was not necessary to include transverse reinforcement to prevent buckling when yield stress $f_{y, c}$ was lower than $475 \mathrm{MPa}$. This conclusion was deduced by taking $\alpha_{s}=0$ and $\alpha_{c}=\alpha_{c, \text { inf }}$ ? $\alpha_{c, r e f}$. For this case $\left(f_{y, c}=475 \mathrm{MPa}\right)$, $k_{c s}>30$, and if (7) was substituted in (3), the following equation was satisfied: $\sigma_{c r i t}=1.05 \cdot f_{y, c}=\sigma_{\text {lim }}$ (it was taken on the security side that $\sigma_{\text {lim }}=1.05 \cdot f_{y, c}$. For those steels with a yield stress above $475 \mathrm{MPa}, \alpha_{s}$ could not be null.

\section{Summary and conclusions}

Design recommendations were proposed to calculate the required tie spacing in the elements made with normal and high strength concrete, and both with and without fibers, to delay reinforcement buckling. A comparison was made between the design recommendations of
Table 6

Determination of required limit stress, and strain and stiffnesses $\alpha_{c}$ and $\alpha_{s}$.

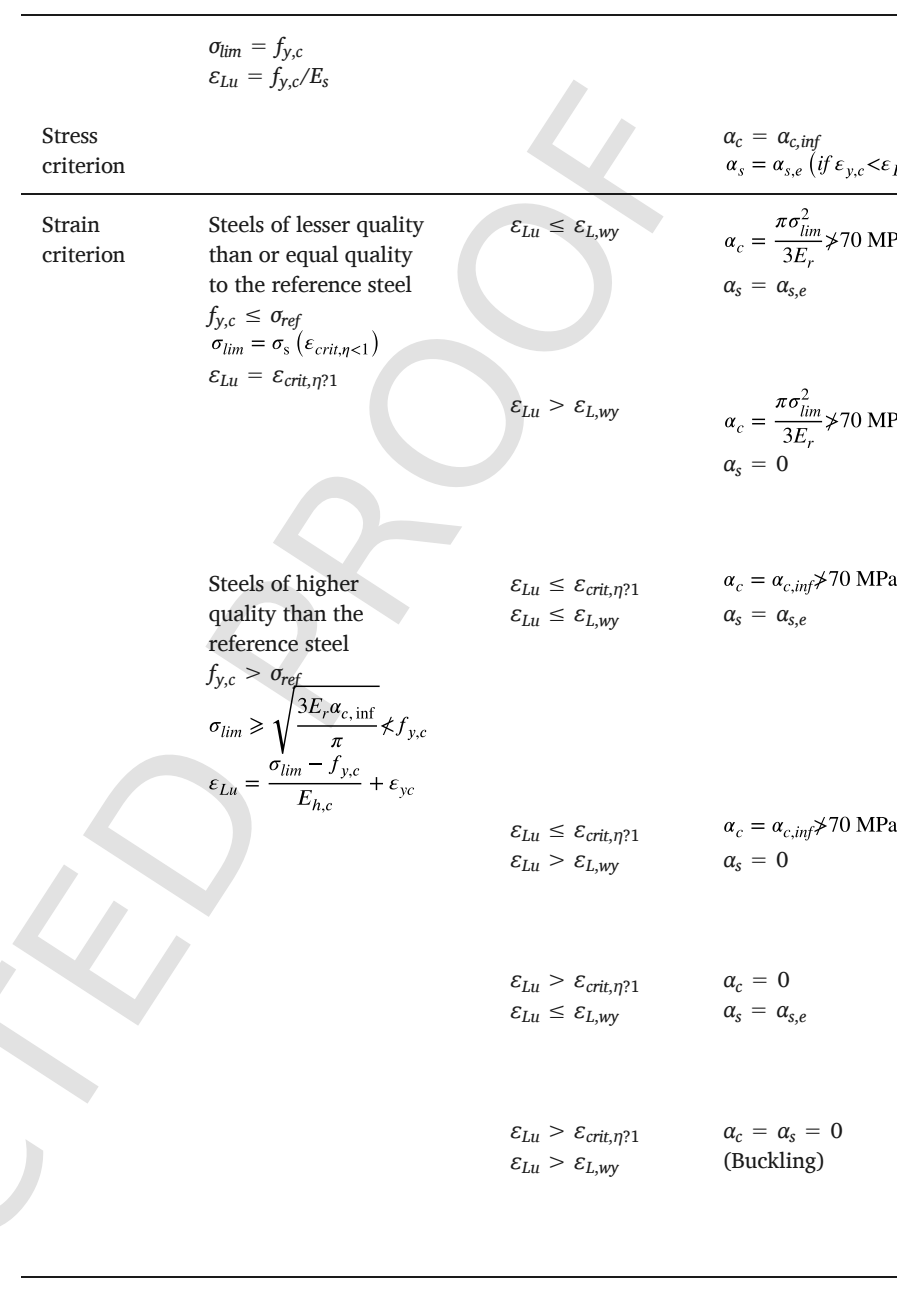

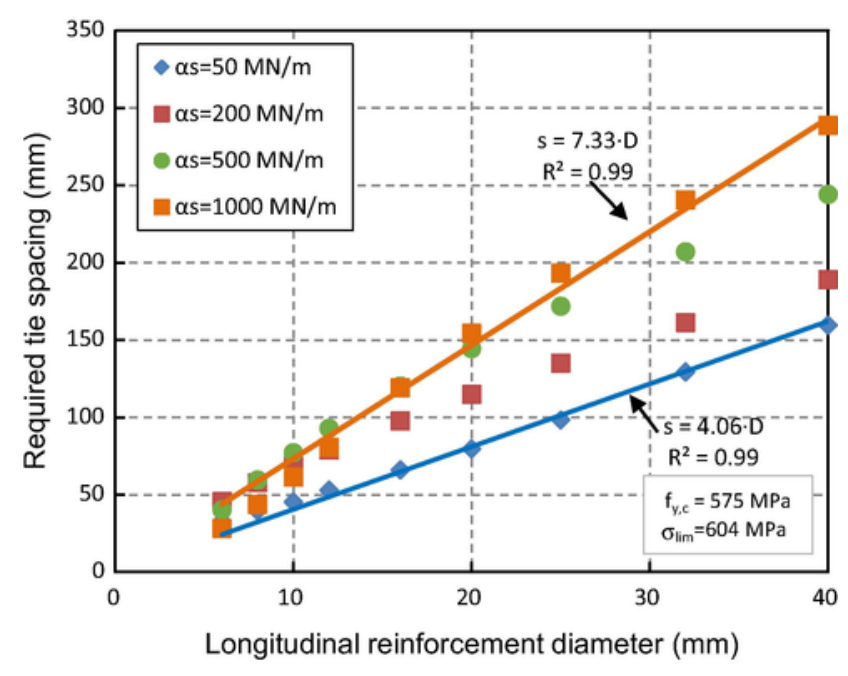

Fig. 15. Required tie spacing for fiber-reinforced concretes with $\alpha_{c}=70 \mathrm{MPa}$, for several $\alpha_{s}$ values and for the reference steel. 
the codes and the proposed one. The conclusions of the proposed design recommendations are as follows:

- For concretes without steel fibers, an expression to calculate tie spacing $s$ was proposed, which depended on required limit stress $\sigma_{\text {lim }}$ and the reduced modulus of compressed bar $E_{r}$, among other parameters. Two criteria to define required limit stress were proposed: (1) in stresses, the bar did not buckle for stresses lower than yield stress $f_{y, c}$ ; (2) in strains, the bar did not buckle for strains lower than required ultimate strain $\varepsilon_{L u}$. This latter criterion allowed to define the minimum separation needed to ensure that the bar did not buckle before stirrups were yielded.

- For the elements made with concrete without steel fibers, and based on the strain criterion, we proposed arranging a maximum required tie spacing that equaled 4D, where $\mathrm{D}$ was the longitudinal reinforcement diameter. Based on the stresses criterion, we proposed a maximum required tie spacing that equaled 30D.

- For fiber-reinforced concretes, a procedure to calculate the maximum required separation was proposed that depended on the adopted design criterion (stress or strain).

- For fiber-reinforced concretes, applying the model resulted in transverse reinforcement not being necessary to delay buckling in the following cases: (1) if the required ultimate strain was lower than the strain at which the bar yielded $\left(\varepsilon_{L u}\right.$ ? $\left.\varepsilon_{y, c}\right)$; (2) if $\varepsilon_{y, c} ? \varepsilon_{L u}$ ? $\varepsilon_{c r i t, \eta ? 1}$ and the yield stress in compression was lower than or equaled $475 \mathrm{MPa}$.

A simplified expression of steel reduced modulus $E_{r}$ is proposed. It takes a null value of the steel plastic modulus in tension. The proposed expression depends exclusively on the yield stress of steel under compression.

In order to propose design recommendations, the model of Pereiro-Barceló and Bonet [2] was extended. This model determines the buckling critical stress of compressed reinforcements. It considers the positive effect of transverse reinforcement, and also the NSC cover with and without fibers. Its use was extended in order to consider HSC with and without fibers.

In order to extend the model, experimental research was conducted. The research included nine HSC columns, three without fibers and six with steel fibers. Columns were subjected to eccentric monotonic loading. The following conclusions were drawn from the experimental results:

- If columns were made of HSC without fibers, buckling occurred after cover spalling. This situation took place when reinforcement achieved a strain that equaled $\varepsilon_{c 85}$. Beyond this strain, the concrete cover no longer existed $\left(\alpha_{c}=0\right)$.

- For concrete made with fibers, a cover stiffness $\alpha_{c}$ value of $70 \mathrm{MPa}$ was obtained for the tested specimens.

- For concrete made with fibers, the strain of the longitudinal bar ( $\left.\varepsilon_{c r i t, \eta ? 1}\right)$ that guaranteed stiffness $\alpha_{c}$ of 70 MPa was experimentally calibrated for both NSC with fiber elements [2] and HSC with fiber elements.

\section{Acknowledgements}

The research presented herein forms part of a research undertaken at the Concrete Science and Technology Institute (ICITECH) of the Universitat Politècnica de València (UPV). The authors are sincerely grateful to the Spanish Ministry of Economy and Competitiveness for the help provided through Project BIA2012-32645, and to the European Union for the financial support obtained from FEDER funds. The au- thors wish to thank the Spanish Ministry of Education, Culture and Sport for Grant FPU12/01451.

\section{References}

[1] J. Su, R.P. Dhakal, J. Wang, W. Wang, Seismic performance of RC bridge piers reinforced with varying yield strength steel, Earthq Struct 12 (2017) 201-211, https: //doi.org/10.12989/eas.2017.12.2.201

[2] J. Pereiro-Barceló, J.L. Bonet, Mixed model for the analytical determination of critical buckling load of passive reinforcement in compressed RC and FRC elements under monotonic loading, Eng Struct 150 (2017) 76-90, https://doi.org/10.1016/ j.engstruct.2017.07.026

[3] B. Bresler, P.H. Gilbert, Tie requirements for reinforced concrete columns, J Proc 58 (1961) https://doi.org/10.14359/7997.

[4] Charles F. Scribner, Reinforcement buckling in reinforced concrete flexural members, J Proc 83 (1986) https://doi.org/10.14359/2648.

[5] M. Papia, G. Russo, G. Zingone, Instability of longitudinal bars in RC columns, J Struct Eng 114 (1988) 445-461.

[6] S.T. Mau, M. El-Mabsout, Inelastic buckling of reinforcing bars, J Eng Mech 115 (1989) 1-17.

[7] S.T. Mau, Effect of tie spacing on inelastic buckling of reinforcing bars, Struct J 87 (1990) https://doi.org/10.14359/2974.

[8] S.J. Pantazopoulou, Detailing for reinforcement stability in RC members, J Struct Eng 124 (1998) 623-632.

[9] R.P. Dhakal, K. Maekawa, Reinforcement stability and fracture of cover concrete in reinforced concrete members, J Struct Eng 128 (2002) 1253-1262.

[10] M.M. Kashani, L.N. Lowes, A.J. Crewe, N.A. Alexander, Nonlinear fibre element modelling of RC bridge piers considering inelastic buckling of reinforcement, Eng Struct 116 (2016) 163-177, https://doi.org/10.1016/j.engstruct.2016.02.051.

[11] R.P. Dhakal, Post-peak response analysis of SFRC columns including spalling and buckling, Struct Eng Mech 22 (2006) 311-330.

[12] M.M. Talaat, K.M. Mosalam, Computational modeling of progressive collapse in reinforced concrete frame structures, ProQuest, 2007.

[13] G. Campione, G. Minafò, Compressive behavior of short high-strength concrete columns, Eng Struct 32 (2010) 2755-2766, https://doi.org/10.1016/j.engstruct. 2010.04.045

[14] G. Campione, Compressive behavior of short fibrous reinforced concrete members with square cross-section, Struct Eng Mech 37 (2011) 649-669.

[15] J. Su, J. Wang, Z. Bai, W. Wang, D. Zhao, Influence of reinforcement buckling on the seismic performance of reinforced concrete columns, Eng Struct 103 (2015) 174-188, https://doi.org/10.1016/j.engstruct.2015.09.007.

[16] R.P. Dhakal, K. Maekawa, Path-dependent cyclic stress-strain relationship of reinforcing bar including buckling, Eng Struct 24 (2002) 1383-1396.

[17] A. Gomes, J. Appleton, Nonlinear cyclic stress-strain relationship of reinforcing bars including buckling, Eng Struct 19 (1997) 822-826.

[18] M.M. Kashani, M.R. Salami, K. Goda, N.A. Alexander, Non-linear flexural behaviour of RC columns including bar buckling and fatigue degradation, Mag Concr Res (2017) 1-17, https://doi.org/10.1680/jmacr.16.00495.

[19] M.M. Kashani, Size effect on inelastic buckling behavior of accelerated pitted corroded bars in porous media, J Mater Civ Eng 29 (2017) 04017022.

[20] M.M. Kashani, A.J. Crewe, N.A. Alexander, Structural capacity assessment of corroded RC bridge piers, Proc Inst Civ Eng - Bridge Eng 170 (2017) 28-41, https:// doi.org/10.1680/jbren.15.00023.

[21] A. Shterenlikht, M.M. Kashani, N.A. Alexander, G. Williams, A.J. Crewe, Autotuning of isotropic hardening constitutive models on real steel buckling data with finite element based multistart global optimisation on parallel computers, Model Simul Eng 2017 (2017) 1-10, https://doi.org/10.1155/2017/6132106.

[22] Fomento EM, Hormigón ECP. EHE-08: Instrucción de Hormigón Estructural : con comentarios de los miembros de la Comisión Permanente del Hormigón; 2008.

[23] EN 1998-1; Eurocode 8: Design of structures for earthquake resistance - Part 1: General rules, seismic actions and rules for buildings; 2004.

[24] EN 1998-2; Eurocode 8: Design of concrete structures - Part 2: Bridges; 2005

[25] ACI Committee 318. ACI 318-14: Building Code Requirements for Structural Concrete and Commentary; 2014.

[26] K.E. Caballero-Morrison, J.L. Bonet, J. Navarro-Gregori, J.R. Martí-Vargas, Behaviour of steel-fibre-reinforced normal-strength concrete slender columns under cyclic loading, Eng Struct 39 (2012) 162-175, https://doi.org/10.1016/j.engstruct. 2012.02.003.

[27] K.E. Caballero-Morrison, J.L. Bonet, J. Navarro-Gregori, P. Serna-Ros, An experimental study of steel fiber-reinforced high-strength concrete slender columns under cyclic loading, Eng Struct 57 (2013) 565-577, https://doi.org/10.1016/j. engstruct.2012.06.052.

[28] A.M. Khajeh, M. Attard, Lateral behaviour of concrete, World Acad Sci Eng Technol 59 (2011) 940-945.

[29] W.P. Lokuge, J.G. Sanjayan, S. Setunge, Stress-strain model for laterally confined concrete, J Mater Civ Eng 17 (2005) 607-616, https://doi.org/10.1061/ (ASCE)0899-1561(2005) 17:6(607).

[30] E. Montoya, F.J. Vecchio, S.A. Sheikh, Compression field modeling of confined concrete: constitutive models, J Mater Civ Eng 18 (2006) 510-517, https://doi. org/10.1061/(ASCE)0899-1561(2006) 18:4(510). 
[31] E. Osorio, J.M. Bairán, A.R. Marí, Lateral behavior of concrete under uniaxial compressive cyclic loading, Mater Struct (2012) https://doi.org/10.1617/ s11527-012-9928-9.

[32] Asociación española de normalización y certificación, AENOR. UNE-EN 14651:2007. Método de ensayo para hormigón con fibras metálicas. Determinación de la resistencia a la tracción por flexión (límite de proporcionalidad (LOP), resistencia residual; 2007.

[33] L.L. Dodd, J.I. Restrepo-Posada, Model for predicting cyclic behavior of reinforcing steel, J Struct Eng 121 (1995) 433-445.

[34] EN 1992-1-1; Eurocode 2: Design of concrete structures - Part 1-1: General rules and rules for buildings; 2004

[35] Asociación española de normalización y certificación, AENOR. UNE-EN 12390-3.Ensayos de hormigón endurecido - Parte 3: Determinación de la resistencia a compresión de probetas; 2000.

[36] AENOR. Spanish Association for Standards and Certification. UNE-EN 10002-1. Metallic materials. Tensile testing. Part 1: Method of test at ambient temperature; 2002.
[37] Collins Michael P., Mitchel Denis, Macgregor James G. Structural design considerations for high-strength concrete. Concr Int 1993: p. 27-34.

[38] L. Leite, J.L. Bonet, L. Pallarés, P.F. Miguel, M.A. Fernández-Prada, Experimental research on high strength concrete slender columns subjected to compression and uniaxial bending with unequal eccentricities at the ends, Eng Struct 48 (2013) 220-232, https://doi.org/10.1016/j.engstruct.2012.07.039.

[39] G. Campione, M. Fossetti, M. Papia, Behavior of fiber-reinforced concrete columns under axially and eccentrically compressive loads, ACI Struct J 107 (2010) 272-281.

[40] Eurocode 2: Design of concrete structures (Draft); 2016.

[41] Fib Model Code for Concrete Structures 2010 (MC2010). Lausanne. International Federation for Structural Concrete; 2010; n.d.

[42] Paultre P, Eid R, Langlois Y, Lévesque Y. Behavior of steel fiber-reinforced high-strength concrete columns under uniaxial compression read more: <http:// ascelibrary.org/doi/abs/10.1061/\%28ASCE\%29ST.1943-541X.0000211 > . ASCE; 2010. p.136. 